\title{
Thermal and Structural Behavior of Filters and Windows for Synchrotron X-ray Sources
}

\section{Z. Wang, U. Hahn, R. Dejus, and T. Kuzay Experimental Facilities Division}

\section{DISCLAIMER}

This report was prepared as an account of work sponsored by an agency of the United States Government. Neither the United States Government nor any agency thereof, nor any of their employees, makes any warranty, express or implied, or assumes any legal liability or responsibility for the accuracy, completeness, or usefulness of any information, apparatus, product, or process disclosed, or represents that its use would not infringe privately owned rights. Reference herein to any specific commercial product, process, or service by trade name, trademark, manufacturer, or otherwise does not necessarily constitute or imply its endorsement, recommendation, or favoring by the United States Government or any agency thereof. The views and opinions of authors expressed herein do not necessarily state or reflect those of the United States Government or any agency thereof.

\section{May 13, 1993}

\section{Advanced Photon Source Argonne National Laboratory}




\section{DISCLAIMER}

Portions of this document may be illegible in electronic image products. Images are produced from the best available original document. 


\section{Contents}

1. Introduction: Use of Filters and Windows in the Front End Designs

2. An Interactive Code for 3D Graphic Viewing of Absorbed Power in

Filters/Windows and a New Heat Load Generation Algorithm for the Finite Element Analysis

3. Failure Criteria and Analysis Methods for the Filter and Window Assembly

4. Comparison with Test Data and Existing Devices in HASYLAB

5. Cooling the Filter: Radiation Cooling or Conduction Cooling?

6. Consideration of Window and Filter Thickness: Thicker or Thinner?

7. Material Selection Criteria for Filters/Windows

8. Photon Transmission through Filters/Windows

9. Window and Filter Design for APS Undulators

10. Window and Filter Design for APS Wigglers

11. Window Design for APS Bending Magnet Front Ends

12. Conclusions and Suggestions 


\section{Introduction: Use of Filters and Windows in the Front End Designs}

Windows are used to separate different vacuums between the front end and the beamline in synchrotron radiation facilities. Usually, windows are made of low-atomicnumber material so that most of the photons can pass through the window. In order to detect a potential vacuum failure through the window, a double window assembly is used, and a gas like helium fills the space between two windows. However, some insertion devices (IDs) are so powerful that the window itself cannot survive the huge heat load imposed by the beam. Filters are then used to absorb low energy photons before the beam passes through the window, in which case the window absorbs much less power and can operate safely.

When designing a filter/window assembly, it is very important to use the correct failure criteria and correct analytical method to predict thermal and structural behavior and safety in the design of a filter/window assembly subject to synchrotron $x$-ray radiation. Many authors [1-6] have performed such analyses and experiments. To predict the failure of the window, a maximum shear stress theory has been widely used [1-6], which says that when the maximum shear stress becomes equal to half of the yield stress, i.e.,

$$
\tau_{\max }=\sigma_{y} / 2,
$$

this stress state will be in yield, where $\tau_{\max }$ is the maximum shear stress and $\sigma_{y}$ is the yield stress. This theory can be used to predict whether a stress point in the structure goes into yield or not. However, this theory is not successful in predicting the failure of the window assembly. For instance, Shen et al. [2] were unable to use the maximum shear stress theory to predict the failure of beryllium windows. At the failure load level, the calculated maximum equivalent stress from a finite element code was found to be four times greater than the yield stress for Be material.

The possible reasons for this discrepancy could be that, first, yielding was not the failure mode in the test. The failure criteria should correspond to the failure phenomena. When some locations in the structure go into yield, additional load can still be added before the window finally breaks. A typical measurement, e.g., maximum tensile stress or strain, should be compared with the value at break. It is obvious that the failure criteria used should be consistent with the failure mode. Furthermore, a nonlinear finite element analysis should be performed for the window using a thin shell/plate element.

The fact that one specific location goes into yield does not necessarily mean that the whole structure will fail. For example, due to stress concentration, a stress state near a small hole of a plate under uniform tension can be much higher than the average stress. With an increase in the load, this point will first go to yield while the remaining structure can still withstand higher loads. Many structural codes have incorporated such a plastic design concept to take advantage of stress redistribution due to plastic deformation. Under the normal working conditions of a filter/window assembly, however, plastic deformation cannot be allowed, because the beam will be on and off for many cycles during the life time. Plastic deformation of a window in the working 
cycle can result in low cycle fatigue. But this loading capability can be used as a safety reserve against abnormal situations, such as a sudden increase in the thermal stress due to loss of cooling, etc. When a failure theory is used in the analysis of a structure, the theory should be consistent with the criteria that we define as failure. For example, if a structure could buckle, the typical stress on the structure should be smaller than the buckling stress. If a structure could fracture, a fracture theory should be used to predict the failure. If a structure could fail due to excessive deformation, the deformation caused by the working load should be compared with the allowable deformation. Sometimes more than one failure theory is needed to predict the failure of a structure. In many cases, a structure can fail in many different ways; consequently, different theories have to be used to guarantee the safety of that structure. For example, when a pressure vessel is designed according to ASME pressure vessel and piping code (such as a cylindrical container), the code requires that many different categories of stress and different combinations have to be checked against different allowable values. These reflect the many different failure phenomena of a pressure vessel, such as cracks, low cycle fatigue, plastic deformation, shakedown, etc.

In the case of filters and windows, all the possible types of failure should be identified and checked with corresponding criteria. The analysis method should enable one to get all the information needed by these different criteria. Many factors influence the failure modes of the filter/window assembly such as the ratio of thickness to the span of the foil, the filter/window material, load conditions, etc.

To study the safety of the filter/window assembly subject to synchrotron x-ray radiation, the failure criteria and analysis models are investigated first. Then, appropriate failure criteria and analytical method were developed, and predictions were compared with the available experimental results. A consistent trend was found between the analysis and the experimental results. The new analytical methods and failure criteria were then utilized to study the possibility of using diamond, carbon/graphite, and $\mathrm{Be}$ as filter and window materials for the APS undulators, wigglers, and bending magnet devices. Conclusions on failure and survival of the windows are offered.

\section{An Interactive Code for 3D Graphic Viewing of Absorbed Power in Filters/Windows and a New Heat Load Generation Algorithm for the Finite Element Analysis}

When a synchrotron beam passes through a thin foil, part of the radiation is absorbed. The absorbed part depends on several factors. The material from which the foil is made plays a very important role. Low- $Z$ materials absorb only the low energy photons, and high-Z materials absorb both low energy photons and higher energy photons.

Software, such as PHOTON2 [7] can be used to calculate the absorbed power from a bending magnet or wiggler source. The problem, however, remains as to how to use the output data from a code such as PHOTON2 for a finite element thermal analysis code such as ANSYS [8]. A thermal load input for a finite element analysis is typically composed of a set of heat generation rates or other equivalent data for the elements. 
Usually the grid for absorption calculations is much different from those in the finite element model for a thermal structural analysis. For example, PHOTON2 uses an equal energy step to decide the grid, while the element grid in ANSYS can be arbitrary. A interface must be designed to convert the data from PHOTON2 to ANSYS.

A straightforward way to convert the data is to hand-calculate the power for each node or element and then type the data into the code. This however becomes a very tedious operation. Because for every change made to the finite element model or every change of beamline parameter, the data must be recalculated and reentered. One way to solve this problem is to curve-fit the discrete data and use curve-fitted formulae in the finite element code to generate the heat load. This has several disadvantages. It is time consuming because of the need to run a second code for generation of the data, curve-fitting, and doing the data check, etc. Additionally, because there is no generality for different beamlines or different parameters, the above work must be repeated for each case. Any error in the power profiles due to curve-fitting causes errors in the analysis. A different approach was developed to solve this problem in a practical and consistent way. A program for ID power profile was written in ANSYS Parametric Design Language (APDL) [8] that is applicable to any ID. This program is implemented as an ANSYS command with input parameters of peak magnetic field, deflection parameter, length of ID, and distance from the source. Once the command is issued, the entire heat load is automatically generated by the code [9].

This code has been further improved by adding more functions that greatly decrease the work one has to do. A very useful feature is the interactive graphics interface and automatic generation of Postscript files for a hard copy of the total power profile and absorbed power profile on any filter. This code has been extensively used in the filter/window thermal and buckling analyses in this report.

The new functions incorporated in the code include:

- A graphics interface that can interactively show the power profile calculated from the code PHOTON or US (for undulator power absorption calculation) [10]. The graphics can be rotated at any angle to get a good view of the profile. Because graphics yield much more information than digital data, this procedure can also be used as a first-cut check on the power profile.

- The ability to show interactively a $2 \mathrm{D}$ total/absorbed power profile in the horizontal and vertical directions at any cross section.

- The ability to run the code on any computer that supports the $X$ window system. Because the $X$ window system has become a standard window environment, one can run the code from most computer systems.

- The ability to read the data from the US code [10] for the absorbed power calculation from the undulator spectrum.

- The ability to select interactively a filter from a set of filters for absorbed power in that filter or to select total input power. 
- The ability to generate a hard copy of the absorbed power in two different forms: contour or a 3D plot as shown in the examples in Figures 2.1 and 2.2. There is a further option for color or black/white.

- The capability of considering the absorption depth effect of the material, such as in a mirror, photon shutter, etc. This can be used to validate the assumption of surface absorption, which assumes that all the heat loads are applied only on the surface of material. This also enables one to perform a more precise thermal deformation analysis when it is needed. The code will generate a 3D heat load in both the horizontal and vertical directions, as well as in depth in the beam direction.

In summary, a code has been developed to be used as a interface from a photon absorption calculation code to a finite element analysis code. This interface includes capabilities of interactive graphics output on a computer screen and black-white or color hard copy to a printer.

\section{Failure Criteria and Analysis Methods for the Filter and Window Assembly}

When the filter/window absorbs radiation, the temperature in these components rises. Due to thermal expansion, compression stresses are produced. The larger the temperature difference, the larger the compression stresses. At a certain level of compression stress, the structure buckles. Also the tensile stress at the boundary or due to bending in the assembly can cause breakage. High temperatures in the assembly can cause melting or evaporating of the filter/window or an unacceptable amount of outgassing. Hence, at least two categories of criteria should be satisfied when a filter/window assembly is being designed:

First, the maximum temperature should be less than the melting or evaporating point of the material and less than the maximum outgassing temperature with some proper safety margin.

Second, the stress state should be safe with a proper safety margin.

The first category is straightforward. The second one is more complex to handle. The question is: what is a safe stress state? To guarantee safety, we have to guard against all possible failures. These possible failures include: excessive deformation of the assembly, low cycle fatigue due to plastic deformation in each loading and unloading cycle; and elastic or plastic buckling of the filter/window due to excessive compression stress in the filter/window.

From the above discussion, the analysis and design of the filter/window assembly should be composed of at least the following steps:

1. Initial design of filter/window assembly includes selection of material, thickness, cooling method, dimensions, etc. The total thickness of the filter/window assembly should satisfy the criteria that the number of photons at the minimum usable energy be 
larger than a certain fraction of the total, i.e., the original photon count, before passing through the assembly:

$$
P_{E \min } \prod_{n} f^{i} E_{\min } \geq k P_{E \min },
$$

where $E_{\min }$ is the minimum photon energy to be used, $P_{E \min }$ is the total number of photons at energy $E_{\min }$; and $k$ is the fraction that, by design, must pass through the filter/window assembly; $f_{E \min }$ is the photon transmission at energy Emin through ith filter/window; $\boldsymbol{n}$ is the total number of filter/windows. The factor $\mathrm{k}$ and the minimum energy $E_{\min }$ are decided by the beamline users. Canceling of $P_{E \min }$ from both sides of Eq. (2)' yields:

$$
\prod_{n} f^{i}{ }_{E \min } \geq k .
$$

2. Calculation of absorbed power in the filter/window according to the particular beamline and the distance of the filter/window assembly from the source.

3. Use of the thermal load from step 2) to perform a thermal analysis, by finite element method or analytical method. (A temperature-dependent material conductivity should be used for strongly temperature-dependent materials.)

4. If the maximum temperature from step 3 ) ( $T_{\max }$ ), is larger than the melting or evaporating temperature of the material $\left(T_{m}\right)$ or larger than the temperature, at which outgassing becomes unacceptable (To), the filter/window assembly must be redesigned. In other words, the following criteria have to be satisfied for a successful design:

$$
T_{\max }<\mathrm{T}_{\mathrm{m}}
$$

and

$$
T_{\max }<\mathrm{T}_{0} .
$$

5. With the temperature field from step 3), perform thermal stress and deformation analysis on the structure with temperature-dependent material properties if the material properties are temperature dependent. The maximum Mises stress or equivalent stress $\sigma_{\max }$ should be smaller than the yielding stress of the material $\sigma_{\mathrm{s}}$ :

$$
\sigma_{\max }<\sigma_{\mathrm{s}}
$$

This is an equivalent of equation (1), and it will guarantee that no low cycle fatigue will occur under normal working conditions.

The maximum tensile stress $\sigma_{\mathrm{tmax}}$ should not surpass the tensile strength of the material $\sigma_{t}$ :

$$
\sigma_{\mathrm{tmax}}<\sigma_{\mathrm{t}}
$$


which ensures that the material will not break. This is extremely important for filters/windows made of low-tensile-strength material, such as carbon. For some materials, such as ductile material, maximum tensile strain should be less than the allowable tensile strain:

$$
\varepsilon_{\mathrm{tmax}}<\varepsilon_{\mathrm{t}}
$$

The maximum deformation of the filter/window assembly $\Delta_{\max }$ should be less than the allowable deformation $\Delta a$ :

$$
\Delta_{\max }<\Delta_{\mathrm{a}}
$$

This rule can be relaxed if no limit is put on the maximum deformation.

Buckling can be checked in many ways. Finite element analysis can be used. A good approximation is to use an analytical solution to get the maximum buckling stresses. For windows, if the two maximum compression stresses $\sigma_{x}$ and $\sigma_{y}$ are about the same, then the larger one (of $\sigma_{x}$ and $\sigma_{y}$ ) has to be șmaller than the buckling stress:

$$
\max \left\{\sigma_{\mathrm{x}}, \sigma_{\mathrm{y}}\right\}<\sigma_{\mathrm{b}}
$$

where $\sigma_{b}$ is given by Timoshenko [11]:

$$
\sigma_{b}=4.82 \mathrm{E}(\mathrm{t} / \mathrm{h})^{2}
$$

for a clamped square plate, and

$$
\sigma_{b}=3.3 E(t / h)^{2}
$$

for a clamped rectangular plate, if the ratio of the width and the height of the window is large enough. Here $t$ is the thickness, $h$ is the height of the filter/window, and $E$ is the Young's modulus of the material. For a clamped edge square plate with onedimensional uniform compression, $\sigma_{\mathrm{b}}$ is given by:

$$
\sigma_{b}=9.10 E(t / h)^{2} .
$$

For a rectangular plate with different compression stresses $\sigma_{x}$ and $\sigma_{y}$, some calculation is needed to get the $\sigma_{\mathrm{b}}$. One can use the following equation [11]:

$$
\left(\sigma_{x}+\frac{a^{2}}{b^{2}} \sigma_{y}\right)_{c r}=\frac{4}{3} \frac{\pi^{2} D a^{2}}{h}\left(\frac{3}{a^{4}}+\frac{3}{b^{4}}+\frac{2}{a^{2} b^{2}}\right) .
$$


If the maximum stress is larger than $\sigma_{\mathrm{b}}$ and the maximum Mises stress is larger than $\sigma_{\mathrm{s}}$, plastic buckling will occur, which is not acceptable. If the maximum compression stress is larger than $\sigma_{b}$ but the maximum Mises stress is less than $\sigma_{s}$, elastic buckling will occur. Because thermal stress is different than mechanical stress in the sense that deformation can relax the thermal stress and the postbuckling load of the plate is increasing with the deformation, one might suggest that the postbuckling behavior be used to design the filter/window assembly. However, a careful study including experimental verification should be carried out, and a larger deformation postbuckling analysis has to be performed and experimental tests should be done before the postbuckling behavior can be considered in the design.

The possible air pressure should be considered in the stress analysis. The pressure-induced stress should be evaluated separately or/and in combination with other stresses such as thermal stress from absorbed power.

Because there may be many other uncertainties in the analysis, it will be a good practice to verify the analytical model with test data, existing filter/window assemblies, and analytical results from other sources.

6. The last step should be tests of prototype based on the design. Further improvements in the design should be done in parallel with the analysis.

The above suggested criteria are based on the assumption that materials used in the filter/window assembly are ideal and no 'hot-spot' effect is discussed here. The 'hotspot' effect is caused by material impurity and means that at a very small part of the material, the absorption of photons is significantly higher than at other parts of the material. The 'hot-spot' effect should be avoided by material specification in the design. In the following sections, the above suggested design and analytical methodology is used for the filter/window assembly analysis.

In summary, in design and analysis of a filter/window assembly, all possible failure modes should be identified and a corresponding failure criteria should be used for each failure mode.

\section{Comparison with Test Data and Existing Devices in HASYLAB}

Two Be window assemblies have been tested at the Photon Factory $[1,4]$. The tests showed that one window buckled due to thermal stress from the absorbed power and the other buckled then evaporated (possibly due to the fact that buckled windows absorb more power and the maximum temperature rose above the melting temperature of $\mathrm{Be}$ ) as shown in Figs. 4.1 and 4.2, respectively.

To verify the above failure criteria and analysis methodology, a series of analyses on the Photon Factory EMPW-28 insertion device were performed [12] and then compared with the test data. First, the total absorbed power on a 300-micron-thick $\mathrm{Be}$ window was calculated [13] by both the PHOTON2 code and an OEHL code [14]. The results from PHOTON2 seem to be in good agreement with the test data. A thermal 
analysis from case $A$ in references $[1,4]$ was then carried out. The temperature profile along the vertical axis showed very good agreement with the data, as in Figs. 4.3 and 4.4. Before performing thermal buckling analysis, the ANSYS code was first benchmarked by doing two buckling analyses on a cylindrical shell: one with uniform axial compression and another with equivalent uniform temperature increment. Both results agreed and also agreed with the experimental results [11]. The thermal buckling analysis was then carried out for case $A$ in references $[1,4]$. The buckling load factor was found to be about 0.85 to 0.9 . This is consistent with the experimental results in references $[1,4]$.

Thermal buckling load has also been calculated for the case in [2], and was found to agree very well with the thermal load in [2]. In the cases in references $[1,4]$ and [2], buckling was the failure mode of the windows tested. Therefore, buckling should be the failure criteria that is applied rather than yielding.

A comparative analysis based on the above methodology has also been performed on a HASYLAB Doris graphite/Be window assembly [15]. The assembly has been in operation for a long time and has no known problems. The filter thickness is $0.13 \mathrm{~mm}$, and the window thickness is $1 \mathrm{~mm}$. The size of the window is $15 \mathrm{~mm} \times 80 \mathrm{~mm}$. The total absorbed power on the window is $410 \mathrm{~W}$. Thermal analysis shows that the maximum temperature of the window is $172.7^{\circ} \mathrm{C}$, and the minimum temperature is 97 ${ }^{\circ} \mathrm{C}$. The temperature difference is $75.7^{\circ} \mathrm{C}$. The maximum von Mises stress from thermal stress analysis is $265 \mathrm{MPa}$, less than the yielding stress for the material, 300 $\mathrm{MPa}$. The maximum compression stress in the horizontal direction is $293 \mathrm{MPa}$, and the maximum compression stress in the vertical direction is $223 \mathrm{MPa}$. So, the assembly is proved to be safe from the analysis, which is consistent with the real situation.

A second analysis then was performed for the same filter but with only a 0.4-mmthick Be window. The total absorbed power on the window is $200 \mathrm{~W}$. The maximum temperature of the window is $141.6^{\circ} \mathrm{C}$, and the minimum temperature is $60^{\circ} \mathrm{C}$. The maximum Mises stress from the thermal stress analysis is $278 \mathrm{MPa}$, also less than the yielding stress of $\mathrm{Be}$. The maximum compression stress in the horizontal direction is $312 \mathrm{MPa}$ and in the vertical direction is $222 \mathrm{MPa}$. The buckling load factor is about 2.07. The buckling stress is $704 \mathrm{MPa}$ from the equation (9), which agrees very well with the finite element result here $(312 \mathrm{MPa} \times 2.07=645 \mathrm{MPa})$. Hence, by changing the window thickness from $1.0 \mathrm{~mm}$ to $0.4 \mathrm{~mm}$ the assembly is still safe, and, if the yielding stress of $\mathrm{Be}$ material is $300 \mathrm{MPa}$, the safety margin has not changed much. It is 1.13 for a $1.0-\mathrm{mm}$ window and 1.08 for a $0.4-\mathrm{mm}$ window.

The comparative analysis of the filter/window design in HASYLAB has shown that the above design criteria are consistent with existing filter/window assemblies, and the above failure criteria can define the safety domain of the assembly.

\section{Cooling the Filter: Radiation Cooling or Conduction Cooling?}

When designing the cooling method for the filter/window assembly, one can choose between two methods: radiation cooling or conduction cooling. What are the pros and cons of each method? 
A comparison has been carried out that uses the same analysis model but with the different cooling methods. It was found that the maximum stress in the filter is smaller with radiation cooling than with convection cooling. The reason is very simple. With radiation cooling, almost all of the heat dissipates into the surroundings from which the heat is generated, and the temperature distribution tends to be more uniform and hence yields smaller stresses. Because the thermal stress is smaller, the window or filter can be made thinner so that more low energy photons can pass through. Because the total energy emitted is proportional to the absolute temperature to the fourth power, the maximum temperature changes very slowly as the total absorbed power increases. For example, if the absorbed power increases by a factor of three, the maximum absolute temperature only increases by a factor of 1.3. However, the corresponding thermal stress decreases because the temperature difference decreases. With convection cooling, the heat travels a distance to the cooling boundary. The temperature difference is proportional to the travel distance as well as the total heat load. The resulting thermal gradients are larger than those found with radiatively cooled filters. Hence, the stresses found in conductively cooled filters are larger than those found in the radiatively cooled filters.

However, the maximum temperature in the filter with radiation cooling is much higher than that with convection cooling. In addition, the surrounding filter box has to be cooled. Fortunately, some materials such as graphite can tolerate very high temperatures without causing problems. Because there is no vacuum tightness required in filters, no sealing is needed when they are attached to the frame.

Table 5.1 lists the results from four different analyses. Case 1 and case 2 are from APS Undulator $A$ with a gap size of $1.5 \mathrm{~cm}$, which corresponds to $K=1.55$. The graphite filter thickness is $280 \mu \mathrm{m}$ for both cases. However, case 1 is cooled only by radiation, and case 2 is cooled by radiation and conduction. Case 3 and case 4 are similar to case 1 and case 2 but are from a APS Wiggler All beam. The graphite filter thickness is $300 \mu \mathrm{m}$. In all four cases, the filter size is $10 \mathrm{~mm} \times 72 \mathrm{~mm}$.

Table 5.1 Comparison of analysis results of radiatively cooled filters vs. conductively cooled filters

\begin{tabular}{|ccrrrrrr|}
\hline Case & $\begin{array}{c}\operatorname{Tmax}^{*} \\
\left({ }^{\circ} \mathrm{K}\right)\end{array}$ & $\begin{array}{c}\operatorname{Tmin} \\
\left({ }^{\circ} \mathrm{K}\right)\end{array}$ & $\begin{array}{c}\max \sigma_{\mathrm{x}} \\
(\mathrm{MPa})\end{array}$ & $\begin{array}{c}\min \sigma_{\mathrm{x}} \\
(\mathrm{MPa})\end{array}$ & $\begin{array}{c}\max \sigma_{\mathrm{y}} \\
(\mathrm{MPa})\end{array}$ & $\begin{array}{c}\min \sigma_{\mathrm{y}} \\
(\mathrm{MPa})\end{array}$ & $\begin{array}{c}\max \sigma_{\mathrm{e}} \\
(\mathrm{MPa})\end{array}$ \\
\hline 1 & 3265 & 1132 & 11.61 & -7.68 & 2.33 & -5.31 & 12.30 \\
2 & 1741 & 400 & 0.13 & -15.16 & 2.45 & -4.89 & 13.52 \\
3 & 2961 & 1698 & 4.08 & -3.16 & 1.13 & -1.34 & 4.14 \\
4 & 2012 & 400 & -0.95 & -29.69 & 2.17 & -21.11 & 29.73 \\
\hline
\end{tabular}

It can be seen that the maximum compression stress in case 4 with convection cooling is many times larger than that with radiation cooling in case 3 . For case 1 and case 2, the difference is not so large because the thermal stress is localized in a very small area due to the small footprint from the undulator. It seems that radiation cooling is preferred for filter designs, if the temperature criteria (3) and (4) can be satisfied. One 
thing should be pointed out, a "pure radiative" cooling is assumed in the above radiation analysis in Table 5.1, i.e., no conduction cooling occurs at the boundary of the filter. In practice, a filter has to be held by a frame that is cooled by a coolant and the cooling of the filter is a combination of radiation and conduction. Due to the contact of the filter with the frame, part of the heat is conducted away through the frame. Depending on the way the filter is mounted on its frame, this conducted part could be significant. The emissivity used in the analysis is 0.5 . This also contributes to the over estimation of the maximum temperature in the filters. That is to say, the maximum temperature in the filter could be much less than that calculated in Table 5.1. The thermal stress can also be higher than that in the table. But as long as the constraint from the mounting frame is kept as little as possible, the thermal stress can still be low.

\section{Consideration of Window and Filter Thickness: Thicker or Thinner?}

The thickness of the filter/window is a key parameter in the design of the assembly. In order to use low energy photons, one should try to design thinner filters/windows. However from the structural safety point of view, it has been proved that the thicker the better. The total thickness should be as thin as possible while satisfying criteria (2) in Section 3. Even given a fixed total thickness of filter/window, there are still options that use either a few thick filters or a large number of thin filters.

A series of analyses have been performed on filters/windows with different thicknesses. With an increase in thickness, it has been shown that the increment of total absorbed power becomes less and less, i.e., the tangent of the total absorbed power vs. thickness curve becomes smaller and smaller. For example in the case of APS Undulator A, the first $250-\mu \mathrm{m}$ graphite filter absorbs about $700 \mathrm{~W}$ of power, while the second $250-\mu \mathrm{m}$ graphite filter absorbs less than $100 \mathrm{~W}$ of power (see Figure 9.5 ). However, the second filter has the same cross sectional area for heat conduction. Both the maximum temperature and the temperature difference decrease with the increment in the filter thickness. The same is true for filters made of other materials, such as $\mathrm{Be}$ and diamond, because photon absorption is similar in all cases. The benefits are two fold. First, the maximum stresses in the filter become smaller; second, with the increase in thickness, the buckling stress increases as the square of the thickness. This is true for both a radiatively cooled and a conductively cooled assembly.

A similar conclusion can also be drawn for a window with a given filter thickness in front of it. Analyses on a 1.0-mm Be window and a 0.4-mm window, both with a 130- $\mu \mathrm{m}$ graphite filter in the front of the window, have shown that the maximum stress on a 1.0$\mathrm{mm}$ Be window is less than that on a $0.4-\mathrm{mm}$ window. Because both cases have a very large buckling stress, the dominant criteria should be that the maximum Mises stress is less than the yielding stress of the material. The maximum stresses for the two cases are very similar. Thus a $1.0-\mathrm{mm} \mathrm{Be}$ window and a $0.4-\mathrm{mm}$ window have almost the same safety factor (as shown in Section 4). The reason is very simple: because a 130$\mu \mathrm{m}$ graphite filter absorbs most of the low energy photons, the absorbed power on the Be window is almost proportional to the increased thickness of the window. Because the increased absorption is offset by the increased conduction area, the maximum 
temperatures of the two windows remain almost the same. However, one cannot decrease the thickness of the window to less than the thickness at which the buckling stress equals the yielding stress of the window material. Further decreasing of the thickness of the window will change the failure mode from plastic deformation or low cycle fatigue to elastic buckling of the window, which has a lower allowable stress than the previous failure mode.

In summary, for a fixed thickness of the filter/window assembly, one should use as few pieces of filter as possible or the thickest filters possible. Once the thickness of the filter/window is decided, the analysis should be performed and checked against the suggested failure criteria in Section 3. After the thickness of the filter is decided, the thickness of the window can be chosen by letting the buckling stress of the window equal the yielding stress of the window material. One can then perform the stress analysis and compare to the failure criteria.

\section{Material Selection Criteria for Filters/Windows}

Material behaviors that are important for a filter/window design include the tensile strength and compression strength, low cycle fatigue behavior, stiffness of the material, thermal conductivity, thermal expansion coefficient, and photon absorption of the material.

As a rule, low- $Z$ materials, such as carbon/graphite, beryllium, and diamond should be given first consideration for windows and filters used to protect the window because low-Z materials absorb less photon energy than do high- $Z$ materials.

Table 7.1 gives the material properties for low-Z materials: beryllium, diamond, and graphite.

Table 7.1 Low-Z Material Properties

\begin{tabular}{|c|c|c|c|}
\hline Material Properties & Diamond & Beryllium & Graphite \\
\hline Atomic Number, $Z$ & 6 & 4 & \\
\hline Density $\left(\mathrm{g} / \mathrm{cm}^{3}\right)$ & 3.5 & 1.85 & 1.74 \\
\hline Thermal Conductivity $(\mathrm{W} / \mathrm{cm}-\mathrm{K})$ & 15 & 2.0 & 8 \\
\hline Thermal Expansion Coefficient $\left(\mathrm{K}^{-1} \times 10^{-6}\right)$ & $1.5-4.8$ & 12 & 1.2 \\
\hline Specific Heat $(\mathrm{J} / \mathrm{Kg}-\mathrm{K})$ & 520 & 190 & $711-1926$ \\
\hline Thermal Diffusivity $\left(\mathrm{cm}^{2} / \mathrm{s}\right)$ & 8.24 & 5.7 & $6.46-2.39$ \\
\hline Young's Modulus (GPa) & 1050 & 320 & $5-10$ \\
\hline Poissons Ratio & $0.1-0.29$ & $0.02-0.08$ & $0.1-0.2$ \\
\hline Melting Point $\left({ }^{\circ} \mathrm{C}\right)$ & NA & 1280 & NA \\
\hline Tensile Strength (GPa) & 2 & $0.3-0.550$ & 0.020 \\
\hline ompression Strength (GPa) & & & 0.060 \\
\hline ield Strength (MPa) & NA & $206-480$ & \\
\hline
\end{tabular}

The following lists the advantages and disadvantages of the low-Z materials listed in Table 7.1. 
Beryllium

Advantages: low atomic number, high Young's modulus, good thermal conductivity.

Disadvantages: high thermal expansion coefficient, hazardous material.

Beryllium is the most popular material for window design. Its biggest advantage is that it has a small atomic number. It absorbs fewer photons than other materials. The Young's modulus is high, and the strength is also high. Its thermal conductivity is not as good as copper but is as good as aluminum.

Graphite

Advantages: high thermal conductivity, can work in high temperature, low thermal expansion coefficient, inexpensive, easy to shape and cut.

Disadvantages: low tensile and compression strength.

Due to the advantages of graphite material, it is widely used as a filter material. It can be made in the form of very thin film (pyretic graphite). It can also be produced in anisotropic forms in structural strength or in thermal properties.

Diamond

Advantages: high Young's modulus, high conductivity, high strength, low thermal expansion coefficient.

Disadvantages: brittle, low temperature tolerance (above $600^{\circ} \mathrm{C}$, diamond tends to become carbon), expensive.

Diamond has about twice the density as does graphite, which means that it will absorb more photon energy than graphite. The failure of a diamond window is likely to be buckling or breaking, if it is thin. Increasing the thickness of a diamond window will also increase the photon absorption and the price of the assembly. Because thermal stress is proportional to $E$ and buckling stress is also proportional to $E$, they offset each other. Because diamond cannot be exposed to very high temperatures, it cannot be used for filters with radiation cooling. A convection-cooled diamond filter will have the same failure mode as a window, due to the clamped edge.

If the beam power is not very high, it is common to use Be as the window material without filters. However, if the beam is very powerful, such as from an APS insertion device, a filter has to be used. Due to the fact that $\mathrm{Be}$ has an atomic number of 4 and graphite has an atomic number of 6 , the filter in front of the Be window absorbs most of the low energy photons. The Be window absorbs only very few low energy photons.

The temperature increment due to absorbed power in the filter is proportional to $Z^{2 / k}[6]$, i.e.,

$\Delta T^{-1} \propto k / Z^{2}$.

The buckling stress is proportional to $E$ from equation (10) 


$$
\sigma_{c r} \propto E
$$

If we assume that the thermal stress is proportional to the thermal strain, i.e.,

$$
\sigma_{t} \propto \varepsilon_{t} E \propto \frac{\alpha E Z^{2}}{k}
$$

comparison of $\sigma_{\mathrm{cr}}$ and $\sigma_{\mathrm{t}}$ shows that the safety factor with respect to buckling is proportional to

$$
\frac{k}{\alpha Z^{2}}
$$

We can compare the factors for diamond and graphite and determine that the ratio is about 1.0 under the condition that both have the same dimensions and boundary conditions. However, a combination of factors should be compared when different designs are being considered. The consideration should include the safety factor of the filter/window assembly as a whole, photon transmission, and the total price of the assembly. Avoid comparing windows or filters individually with the same conditions, such as windows of the same thickness but made of different materials. For example, when comparing the graphite filter/Be window assembly with $\mathrm{Be}$ filter/diamond window assembly, compare the minimum safety factor of all filters and windows with the safety factor of the diamond window, the photon transmission through the assemblies, and the price of the two different designs.

Different safety margins should be specified for different failure modes. Some failures can be catastrophic, such as a break of a window made of brittle material; some are not, such as outgassing due to high temperatures. It is possible that one designed failure mode is buckling and another designed failure mode is low cycle fatigue.

Diamond has high strength and Young's modulus, but it is brittle. Cracks or breakage can result from buckling of the window. Once the window buckles, it fails. Beryllium is a ductile material, the postbuckling behavior can still be considered a part of the safety factor.

\section{Photon Transmission through Filters/Windows}

Photon transmission is a very important factor to consider when designing the filter/window assembly. If the filter is used to protect the window, the thinner the filter, the more easily the low energy photons can pass through the assembly. The final photon transmission determines the maximum total thickness of the filter and window.

Figures 8.1 - 8.14 show the photon transmission for some typical materials for filters/windows (Figures 8.6-8.14 are from [6] and [13]). The thicknesses used in the calculation can be taken as unit thicknesses. If a different thickness is used in the design, one can simply get the value from the curves and calculate the photon transmission as follows: 


$$
P_{\text {total }}=\left(p_{e}\right)^{a} \text {, }
$$

where $a=t / t_{0}$, and $t$ is the thickness of the foil to be calculated, $t_{0}$ is the foil thickness on which the curve value is based, $P_{e}$ is the photon transmission at energy $e$ through $t_{0}$, and $P_{\text {total }}$ is the total photon transmission through a filter of thickness of $t$.

\section{Window and Filter Design for APS Undulators}

A set of analyses are first performed to determine the materials for the filter/window assembly from possible candidate materials (based on original parameters [16]) in which thermal and structural analyses have been performed for various thicknesses of graphite filter and $\mathrm{Be}$ filter. Both wiggler approximations from PHOTON2 and Bessel function approximations from US code for the undulator spectrum have been used to calculate the absorbed power in materials. Comparison has revealed that the wiggler approximation of the undulator spectrum generally overestimates the absorbed power on the filter/window, as shown in Figures 9.1-9.3 for Be filters and graphite filters separately. Dejus et al. [10] have shown that the wiggler approximation is almost the same as a Bessel function approximation along the vertical direction in the central cone part, and the wiggler approximation overestimates the absorbed power in the off-axis region for a Be filter.

The possible material selection is decided by first stage analyses. Graphite filter/Be window assembly analyses are then performed for various gap size of the APS undulator device. The maximum filter thickness is determined for different gaps in such a manner that $50 \%$ of photons at the first harmonic energy corresponding to that gap size can pass through the filter/window assembly.

\section{Carbon/Graphite Filter and Be Window Assembly}

For different thicknesses of graphite filter and two 250- $\mu \mathrm{m}$ Be windows, absorbed power, thermal, and thermal stress analyses were performed. The graphite was assumed to be conductively cooled like a window. Figure 9.4 shows the total absorbed power on a filter and two windows and the maximum temperature on the filter. When the filter thickness is larger than $0.25 \mathrm{~mm}$, the absorbed power on the two Be windows is almost the same. Increasing the thickness of the window has the same effect as increasing the absorbed power and increasing the conduction cross section area. The two effects offset each other. Hence, the maximum temperature will almost be independent of the thickness of the window.

Similar analyses have been performed for carbon filters/Be windows. Basically, the results are similar to those for a graphite filter. In fact, one can substitute the carbon filter for the graphite filter by multiplying its thickness with the ratio of their densities. The absorbed power on the filters and windows is shown in Figure 9.5. The thicker the filter, the smaller the maximum temperature on the filters and windows.

The thermal analyses were then carried out for the filters and windows. The maximum temperatures and temperature increments are shown in Figure 9.6. 
If the filter is cooled by conduction, graphite more than $0.3 \mathrm{~mm}$ thick is needed to avoid buckling. The maximum tensile stress of the filter is $6.8 \mathrm{MPa}$, and the maximum compression stress is $21 \mathrm{MPa}$. These values are less than the tensile strength and compression strength of graphite material. Windows in this case have lower stress levels and are safe.

Because low energy photons from undulators are very important to some users, photon transmissivity analysis has to be checked. Figure 9.7 shows a plot of the photon transmission at $5 \mathrm{KeV}$ though the filter/window assembly. With $0.3 \mathrm{~mm}$ of graphite filter and two $0.25-\mathrm{mm} \mathrm{Be}$ windows, only $20 \%$ of the photons at an energy of $5 \mathrm{KeV}$ can pass through the assembly. The photon transmission criteria (2) in Section 3 might not be satisfied.

\section{Diamond Filter and Be Window}

The analyses were then performed on a proposed diamond filter and $\mathrm{Be}$ window assembly. The analysis show that with a diamond filter thickness of 1000 microns, $T_{\max }$ $=480^{\circ} \mathrm{C}$, and with a diamond filter thickness of 500 microns, $T_{\max }=620^{\circ} \mathrm{C}$. The power absorbed in two successive $\mathrm{Be}$ windows is about $24 \mathrm{~W}$ each in the case of the 1000micron filter and about $38 \mathrm{~W}$ each in the case of the 500-micron filter. For a 250micron-thick Be window with $38 \mathrm{~W}$ total absorbed power, $T_{\max }$ is about $150^{\circ} \mathrm{C}$. The results of the thermal analysis on a 300-micron diamond filter with a fixed edge boundary condition are shown in Figure 9.8. Without excessive filtering, the maximum temperature of the diamond filter can be higher than the maximum working temperature of diamond.

\section{Be Filter and Be Window}

The possibility of using $\mathrm{Be}$ as the filter material is examined next. Thermal and structural analyses have been performed for various thicknesses of Be filter. Both wiggler approximations from PHOTON2 [7] and Bessel function approximations from US [10] for the undulator spectrum have been used to calculate the absorbed power in materials. Figure 9.9 shows the maximum temperature for a conductively cooled filter, the temperature increment, and the absorbed power on the Be filter versus the thickness of the filter.

The temperature difference in the Be filter is too high even in the case of a $2.5-\mathrm{mm}$ thick filter and so is the maximum stress. The high stress could result in plastic deformation or low cycle fatigue failure of the filter assembly. Further increasing the thickness may possibly bring the maximum stress level down, but obviously this will block more and more of the usable low energy photons.

The absorbed power is calculated by the PHOTON2 code. Because the code uses a wiggler approach for spectrum calculations, one has to be careful when using it. Dave Brown [13] analyzed the Photon Factory's test data [4] in the small-K region using PHOTON2. He showed that the absorbed power calculated by PHOTON2 is in very 
good agreement with the test data [4]. Therefore, we can say that the absorbed power calculations for diamond filters for APS Undulator A are on the conservative side.

Comparisons between absorbed power calculated by the wiggler approximations and by direct undulator spectrum calculations using the Bessel function approximations show that the wiggler approximation of undulator spectrum could result in a $30 \%$ to $40 \%$ overestimation of the absorbed power on the filter.

\section{Thermal and Structural Analysis of Different Sizes of Graphite Filter}

If radiation cooling is selected for the filter, then a question arises: what should be the size of the filter? Should a larger filter be used or a smaller one? Or is there an optimal filter size? To address this problem, serial analyses are performed using different size filters. In all cases, a $280-\mu \mathrm{m}$ graphite filter is assumed, but the comparative results should remain the same for filters made of other materials. The filter is assumed to be 24 meters away from the source. The following parameters are used in the analyses: $\mathrm{K}=1.55, \mathrm{E}_{\mathrm{c}}=16.42(\mathrm{KeV})$. The total power of the assumed ID device is $1867 \mathrm{~W}$ and absorbed power on the filter is $484.1 \mathrm{~W}$. Table 9.1 shows the results from these analyses.

From the table, we can see that there is an optimal size for the filter. A large filter will result in a large compression stress, and a small filter will result in a large tensile stress. In our case, the optimal size of the graphite filter is $4 \times 4(\mathrm{~cm})$, which gives a safety factor of about 3.7 in both compression and tensile stress states. All other sizes in Table 9.1 will give a smaller safety factor for the tensile stress state. If the filter size is larger than $4 \times 4(\mathrm{~cm})$, the maximum tensile stress will be smaller than that of $4 \times 4$ (cm) filter, and the maximum compression stress will larger than that of $4 \times 4(\mathrm{~cm})$ filter. That yields a smaller safety factor for the compression stress state.

Table 9.1 Results from thermal and structural analyses for different filter sizes

\begin{tabular}{|ccccccccc|}
\hline $\begin{array}{c}\text { Size } \\
(\mathrm{cm} \times \mathrm{cm})\end{array}$ & $\begin{array}{c}\operatorname{Tmax}^{*} \\
\left({ }^{\circ} \mathrm{K}\right)\end{array}$ & $\begin{array}{c}T \min \\
\left({ }^{\circ} \mathrm{K}\right)\end{array}$ & $\begin{array}{c}\max \sigma_{x} \\
(\mathrm{MPa})\end{array}$ & $\begin{array}{c}\min \sigma_{\mathrm{x}} \\
(\mathrm{MPa})\end{array}$ & $\begin{array}{c}\max \sigma_{\mathrm{y}} \\
(\mathrm{MPa})\end{array}$ & $\begin{array}{c}\min \sigma_{\mathrm{y}} \\
(\mathrm{MPa})\end{array}$ & $\begin{array}{c}\max \sigma_{e} \\
(\mathrm{MPa})\end{array}$ & $\begin{array}{c}\text { Safety } \\
\text { Factor }\end{array}$ \\
\hline $4 \times 4$ & 3030 & 1232 & 5.37 & -15.85 & 5.32 & -15.74 & 15.79 & 3.72 \\
$4 \times 2$ & 3138 & 1404 & 11.69 & -13.22 & 3.33 & -11.06 & 12.28 & 1.71 \\
$4 \times 1$ & 3353 & 1501 & 12.61 & -7.98 & 2.50 & -5.04 & 12.85 & 1.59 \\
$7.2 \times 1$ & 3265 & 1132 & 11.61 & -7.68 & 2.33 & -5.31 & 12.30 & 1.72 \\
$1 \times 1$ & 3556 & 2712 & 7.21 & -5.27 & 7.08 & -4.69 & 7.44 & 2.77 \\
$2 \times 2$ & 3194 & 1789 & 7.70 & -10.95 & 7.24 & -10.98 & 10.96 & 2.60 \\
\hline
\end{tabular}

${ }^{*}$ The $\mathrm{T}_{\max }$ is over-estimated for the same reason as given in Section 5.

Because tensile strength and compression strength are different for materials like graphite, different safety margins should be given to tensile stress and compression stress. The optimal size of a filter should be such that the safety factors for the compression stress and tensile stress state are the same, i.e., the allowable tensile stress in the filter divided by the maximum tensile stress equals that for the compression stress state. For graphite material, the allowable tensile stress is $20 \mathrm{MPa}$, and the allowable compression stress is $60 \mathrm{MPa}$. If the buckling stress is less than the 
allowable compression stress, the buckling stress should be used in place of the allowable compression stress.

In summary, there is an optimal filter size that can best utilize the material properties, i.e., allowable tensile stress and allowable compression stress of the filter material. In the case of our analysis, this optimal size is $4 \times 4(\mathrm{~cm})$ for a $280-\mu \mathrm{m}$ graphite filter.

\section{Static Air Pressure on the Window}

Stress due to air pressure should be considered in the window analysis when vacuum venting is postulated. This usually is the case for a second window. A 250- $\mu \mathrm{m}$ Be window $(1 \mathrm{~cm} \times 8 \mathrm{~cm})$ subjected to only one atmospheric pressure and subjected to both thermal load and one atmospheric pressure is analyzed. The parameters are the same as those above for the optimal filter size analysis. Two $250-\mu \mathrm{m}$ windows follow a $280-\mathrm{mm}$ graphite filter. The analysis applies only to the second Be window. The absorbed power on the window is $22.8 \mathrm{~W}$.

Table 9.2 lists the results from the analysis both with and without the air pressure. It can be seen that the static air pressure accounts for about $67 \mathrm{MPa}$ of maximum stress. This is about $1 / 5$ of the yielding stress of $\mathrm{Be}$. If the failure mode of the window is plastic deformation or low cycle fatigue, the pressure-induced stress accounts for about $1 / 5$ the total failure stress.

Table 9.2 Stress of Be window with and without thermal load and comparison with stress without considering the air pressure

\begin{tabular}{|cccccc|}
\hline & $\begin{array}{c}\max \sigma_{x} \\
(\mathrm{Mpa})\end{array}$ & $\begin{array}{c}\min \sigma_{\mathrm{x}} \\
(\mathrm{Mpa})\end{array}$ & $\begin{array}{c}\max \sigma_{\mathrm{y}} \\
(\mathrm{Mpa})\end{array}$ & $\begin{array}{c}\min \sigma_{\mathrm{y}} \\
(\mathrm{Mpa})\end{array}$ & $\begin{array}{c}\max \sigma_{\mathrm{e}} \\
(\mathrm{Mpa})\end{array}$ \\
\hline Air pressure only & 45.76 & -45.76 & 68.26 & -68.26 & 67.09 \\
Air pressure + Thermal load & 46.58 & -279.71 & 78.68 & -353.82 & 323.12 \\
Thermal Load only & 9.84 & -261.16 & 9.98 & -284.41 & 273.54 \\
\hline
\end{tabular}

Thermal and Structural Analyses for Graphite Filter/Be Window Assembly at Different Device Gap Sizes.

From the above analyses, it seems that the graphite filter and Be window combination is preferred over other material or materials combinations. Also from the previous section's discussion, radiation cooling is preferred for the graphite filter and the fewer pieces the better. Therefore the following filter/window analyses were performed for a graphite filter and a Be window at different device gap sizes.

For different gaps of Undulator $A$, the total power of the beamline and the photon energy of first harmonic are different. The benefits are two fold from increasing the gap size: less total beam power and larger first harmonic photon energy. It is possible that at certain device gap sizes, a filter/window assembly can satisfy the requirements of 
structural integrity and pass through of the fraction of photons at minimum usable energy.

Table 9.3 Maximum Graphite Filter Thickness for Undulator A at Different Gap Sizes

\begin{tabular}{|cccccc|}
\hline Gap size $(\mathrm{cm})$ & Peak Field $(\mathrm{T})$ & Eff. Field $(\mathrm{T})$ & $\mathrm{K}$ & $\mathrm{E}_{1}(\mathrm{KeV})$ & Max Thickness $(\mu \mathrm{m})$ \\
\hline 1.15 & 0.722 & 0.703 & 2.17 & 4.21 & 10 \\
1.30 & 0.622 & 0.609 & 1.88 & 5.10 & 100 \\
1.40 & 0.564 & 0.554 & 1.71 & 5.73 & 160 \\
1.50 & 0.511 & 0.504 & 1.55 & 6.39 & 280 \\
1.70 & 0.421 & 0.417 & 1.28 & 7.73 & 540 \\
1.90 & 0.347 & 0.344 & 1.06 & 9.02 & 1020 \\
2.50 & 0.195 & 0.194 & 0.60 & 12.00 & 3230 \\
3.00 & 0.121 & 0.121 & 0.373 & 13.20 & - \\
3.50 & 0.0751 & 0.0751 & 0.231 & 13.70 & - \\
4.00 & 0.0466 & 0.0466 & 0.144 & .14 .00 & - \\
\hline
\end{tabular}

Table 9.3 lists the maximum graphite filter thickness for different gaps of Undulator A. The maximum thickness of the filter is decided such that $50 \%$ of photons at the first harmonic energy can pass through the assembly. The window is assumed to be composed of two $250-\mu \mathrm{m}$ Be foils. $E_{1}$ in the table is the photon energy at first harmonic.

The analyses proceed from smaller gap sizes. For each gap size, thermal and structural analysis are performed for the graphite filter thickness given in Table 9.3. If either filter or window cannot satisfy any of the criteria in Section 3, the next gap size will be analyzed. The analysis will continue until the corresponding graphite filter thickness can also make the filter/window assembly structurally safe.

For a gap size of $1.15 \mathrm{~cm}$, the previous analysis on different device parameters has shown that at least a 300- $\mu \mathrm{m}$ graphite filter is needed for a safe assembly. Hence, there is no need for analysis of windows with a gap size of $1.15 \mathrm{~cm}$, and we can start from a gap size of $1.30 \mathrm{~cm}$. Table 9.4 lists the analysis results for three gap sizes: 1.3, 1.4 , and $1.5 \mathrm{~cm}$.

From Table 9.4, it is seen that, with a gap size of $1.5 \mathrm{~cm}$, the filter/window assembly can satisfy all the criteria in Section 3 and $50 \%$ of photons at first harmonic can pass through the assembly. With a 280- $\mu \mathrm{m}$ graphite filter and two $\mathrm{Be}$ window, no structural failure is predicted under normal working conditions. Because the stress levels in both windows are similar to the yielding stress of Be material while having a buckling load factor of two or larger, the failure mode will be plastic deformation or plastic-deformation-induced low cycle fatigue. Due to the plasticity of the Be material, the windows can tolerate an abnormal temperature jump over normal temperature by a factor of two. Although the second window absorbs less power than the first one, the stress level is higher than that in the first window due to the atmospheric pressure. During the analysis, if any component of the assembly cannot satisfy any criteria in Section 3, there is no need for further analysis for the remaining components. For example, for a gap size of $1.3 \mathrm{~cm}$, stresses in the first window are too high for it to survive, thus, the analysis for second window is not necessary. 
Table 9.4 Results of the Thermal and Structural Analyses for Different Gap Sizes

\begin{tabular}{|llll|}
\hline Gap Size (cm) & 1.30 & 1.40 & 1.50 \\
\hline K Value & 1.88 & 1.71 & 1.55 \\
Ec (KeV) & 19.84 & 18.05 & 16.42 \\
Thickness of Graphite Filter Thickness $(\mu \mathrm{m})$ & 100 & 160 & 280 \\
Distance from Source (m) & 24 & 24 & 24 \\
Total Power (W) & 2736 & 2264 & 1867 \\
Absorbed Power on Filter (W) & 412 & 444 & 484 \\
(by US a Bessel Function approximation) & $(212)$ & $(243)$ & $(285)$ \\
Absorbed Power on 1st Be Window(W) & 63 & 42 & 25 \\
(by US a Bessel Function approximation) & $(52)$ & $(37)$ & $(24)$ \\
Absorbed Power on 2nd Be Window(W) & 49 & 35 & 23 \\
(by US, a Bessel Function approximation) & $(42)$ & $(31)$ & $(21)$ \\
Max Temperature on Filter (K) & 3260 & 3263 & 3030 \\
Max Mises Stress on Filter(MPa) & 19.9 & 19.0 & 15.8 \\
Max Tensile Stress on Filter(MPa) & 6.8 & 6.4 & 5.4 \\
Max Compression Stress on Filter(MPa) & -29.4 & -19.6 & -15.8 \\
Structurally Safe for Filter? & YES & YES & YES \\
Max Temperature on 1st Window (C) & 260.5 & 191.5 & 134.8 \\
Min Temperature on 1st Window (C) & 35.9 & 32.1 & 29.3 \\
Max Mises Stress on 1st Window (MPa) & 859.2 & 462.2 & 273.5 \\
Max Compression Stress on 1st Window (MPa) & 700.3 & 477.7 & 284.4 \\
Buckling Load Factor & 1.10 & 1.48 & 2.08 \\
Structurally Safe for 2nd Window? & NO & NO & YES \\
Max Temperature on 2nd Window (C) & - & - & 124.2 \\
Min Temperature on 2nd Window (C) & - & - & 28.9 \\
Max Mises Stress on 2nd Window (MPa) & - & - & 287.7 \\
Max Compression Stress on 1st Window (MPa) & - & - & 315.9 \\
Buckling Load Factor & - & - & 10.9 \\
Structurally Safe for 2nd Window? & - & - & YES \\
\hline
\end{tabular}

The absorbed powers on filters/windows calculated by a Bessel function approximation of the undulator spectrum are also listed in Table 9.4 (in parenthesis). It is found that the absorbed powers on the graphite filters for different gaps have the same increments by both approximations when the thickness of the filters change. For example, the absorbed powers on a graphite filter for graphite thicknesses of $100 \mu \mathrm{m}$, $160 \mu \mathrm{m}$, and $280 \mu \mathrm{m}$ are $412 \mathrm{~W}, 444 \mathrm{~W}$, and $484 \mathrm{~W}$, respectively, from the wiggler approximation and are $212 \mathrm{~W}, 243 \mathrm{~W}$, and $285 \mathrm{~W}$, respectively, from Bessel function approximation. The increments are about $32 \mathrm{~W}$ and $40 \mathrm{~W}$ for both approximations. That is to say, the overestimated part of the absorbed power is mainly in the low energy photon region. The thinner the first filter, the larger the fraction of the overestimated part. For a gap size of $1.55 \mathrm{~cm}$, there is $280 \mu \mathrm{m}$ of graphite filter. The absorbed powers for two Be window after the filter are almost identical from both approximations. 
The remaining fraction of energy vs. photon energy are shown in Figure 9.10 through 9.12. They are from Bessel function approximations of undulator spectrum.

In conclusion, the wiggler approximation of undulator spectrum for the calculation of absorbed power on filters/windows has been used for absorbed power analysis, and has been found to overestimate absorbed power in filters/windows. The over-estimated absorbed power is mainly concentrate at low photon energies. If the filter is thick enough in front of a window, the absorbed power of an undulator on windows as determined by wiggler approximation can be expected to give a very good approximation and will be on the safe side. If an assumption is made such that at least $50 \%$ of the photons at the first harmonic energy pass through the filter/window assembly, the filter/window can be used for APS Undulator A only when the gap size is equal to or larger than $1.5 \mathrm{~cm}$. The absorbed power for the first window can be used as a measure for window survival. This absorbed power should be less than 25 watts for the first window and 23 watts for the second window in the case of APS Undulator A.

\section{Window and Filter Designs for APS Wigglers}

From Table 10.1, it is seen that Wiggler Alll is the worst case of all designed APS wigglers. The following window and filter analyses are based on the Wiggler Alll parameters in this table.

For the wiggler, analyses are performed on graphite filters of various thicknesses and two $250-\mu \mathrm{m} \mathrm{Be}$ windows. The absorbed power on the filters and windows versus the thickness of the filter are shown in Figure 10.1 and 10.2. When the thickness is less than $0.25 \mathrm{~mm}$, the absorbed power on the filter increases very rapidly with the thickness. After that, the curve becomes flatter, i.e., the increment rate of absorbed power becomes smaller.

As with the Undulator $A$ analysis, it is found that the absorbed powers on two consecutive Be windows are almost the same when the filter thickness is larger than $0.25 \mathrm{~mm}$. That is to say, the absorbed power on a Be window is proportional to its thickness if there is a graphite filter (at least $0.25 \mathrm{~mm}$ thick) in front of it. The maximum temperature of the window will be a constant regardless of its thickness. The optimal thickness of the window is made such that the buckling stress equals the yielding stress. A window thinner than this value will undergo elastic buckling. A window thicker than this will block more photons.

By using the criteria in Section 3, we can roughly estimate the optimum thickness of the window to be:

$$
t=h \sqrt{\frac{\sigma_{s}}{3.3 E}} \cong 0.21 \mathrm{~mm},
$$

where $\sigma_{\mathrm{s}}$ and $\mathrm{E}$ are from Table 10.1. To consider the divergence and other factors, we use $\mathrm{t}=0.25 \mathrm{~mm}$ for the tentative thickness of the Be window. 


\section{ADVANCED PHOTON SOURCE}

Design Parameters of Various APS Insertion Devices for a Ring Energy of $7 \mathrm{GeV}$ and $100 \mathrm{~mA}$ Stored Current

\begin{tabular}{|c|c|c|c|c|c|c|c|}
\hline \multirow{2}{*}{$\theta$} & \multicolumn{4}{|c|}{ Undulator } & \multicolumn{3}{|c|}{ Wiggler } \\
\hline & $\mathrm{U} 2.8$ & U3.3 & UWI & UWII & $\mathrm{A}_{\mathrm{I}}$ & $A_{\text {II }}$ & $A_{\text {III }}$ \\
\hline Period length $[\mathrm{cm}]$ & 2.8 & 3.3 & 5.5 & 16 & 15 & 15 & 15 \\
\hline Device length $[\mathrm{m}]$ & 2.41 & 2.4 & 2.4 & 4.8 & 1.5 & 2.4 & 4.8 \\
\hline Number of periods & 86 & 72 & 44 & 30 & 10 & 16 & 32 \\
\hline Max. magnetic field $\mathrm{B}_{\mathrm{O}}[\mathrm{T}]$ & 0.382 & 0.704 & 1.14 & 0.315 & 1.0 & 1.0 & 1.0 \\
\hline Characteristic energy $E_{c}[\mathrm{keV}]$ & 12.45 & 22.94 & 37.15 & 10.26 & 32.59 & 32.59 & 32.59 \\
\hline $1 / \gamma[\mathrm{mrad}]$ & 0.073 & 0.073 & 0.073 & 0.073 & 0.073 & 0.073 & 0.073 \\
\hline Max. deflection parameter, $\mathrm{K}$ & 1.0 & 2.17 & 5.86 & 4.7 & 14 & 14 & 14 \\
\hline $\mathrm{K} / \gamma[\mathrm{mrad}]$ & 0.073 & 0.158 & 0.428 & 0.343 & 1.02 & 1.02 & 1.02 \\
\hline Total power $[\mathrm{kW}]$ & 1.09 & 3.69 & 9.67 & 1.48 & 4.65 & 7.44 & 14.89 \\
\hline Peak power $\left[\mathrm{kW} / \mathrm{mrad}^{2}\right]$ & 80.97 & 131.92 & 129.38 & 24.69 & 26.04 & 41.67 & 83.39 \\
\hline Peak power @ PS1 [W/mm²] & 285 & 465 & 456 & 75 & 67 & 111 & 255 \\
\hline$" \quad$ @PS2 [W/mm2] & 199 & 325 & 318 & 53 & 49 & 81 & 182 \\
\hline " $\quad$ @Win $\left[\mathrm{W} / \mathrm{mm}^{2}\right]$ & 144 & 235 & 231 & 40 & 37 & 61 & 134 \\
\hline
\end{tabular}

Table 10.1. Design parameters of various APS insertion devices 
The next step is to use the criteria given in Section 3 for thermal and stress analysis and check against all the criteria.

\section{Thermal Analysis of Filters}

Thermal analyses are then performed for graphite filters of various thicknesses with radiation cooling. An assumption is made that the graphite filter has an emissivity of 0.5 and that two sides can radiate heat. This is equivalent to one side radiating heat but with an emissivity of 1.0. The maximum and minimum temperatures of the filter are shown in Figure 10.3. The minimum temperature of the filter is dependent on the size of the filter. By the radiation law, the total energy emitted is proportional to the absolute temperature to the fourth power. This explains why the maximum temperature increases very little when the thickness of the filter increases more. The maximum temperature difference decreases as the filter thickness increases.

\section{Stress Analysis of Filters}

The maximum stresses decrease as the thickness of the filter increases. According to Table 10.1, the tensile and compression strengths for graphite are $20 \mathrm{MPa}$ and $60 \mathrm{MPa}$, respectively. From Figure 10.4, it can be seen that the filter is safe.

\section{Application of Failure Criteria to the Filter}

Because only high energy photons are to be used and most photons above 10 $\mathrm{KeV}$ pass through the assembly, there is no minimum filter thickness requirement. For graphite material, there is no melting problem and no outgassing problem below 3000 ${ }^{\circ} \mathrm{C}[19]$. The maximum stress level is below the tensile, compression strength and the buckling stress of graphite material.

\section{Thermal Analysis of Windows}

Because the maximum temperature of the window is almost constant if the filter thickness is larger than $0.25 \mathrm{~mm}$ and the filter is safe as discussed above, the analysis of the window is performed on a constant thickness of $0.25 \mathrm{~mm}$ with various thicknesses of filter. The thickness of the filter starts from very thin, then increases until the window is determined to be safe. The corresponding thickness of the filter will be the minimum thickness for a safe filter/window assembly. Figure 10.6 is the temperature contour of a window with a $300-\mu \mathrm{m}$ graphite filter.

Table 10.2 is the tabular form of the maximum and minimum temperatures of the window with different thicknesses of graphite filters. 
Table 10.2. Maximum, Minimum Temperatures and Temperature Difference

\begin{tabular}{cccc}
\hline Filter thickness $(\mu \mathrm{m})$ & Maximum $T(\underline{0})$ & Minimum $T(\underline{0} \underline{\mathrm{C}})$ & $\Delta T=T_{\max }-T_{\min }\left({ }^{0} \underline{\mathrm{C}}\right)$ \\
\hline 100 & 217 & 63 & 154 \\
200 & 162 & 51 & 111 \\
300 & 136 & 45 & 91 \\
\hline
\end{tabular}

\section{Stress Analysis of Windows}

Large deformation nonlinear thermal stress analyses have been performed using the temperature field from the thermal analysis. As expected, the window yields first, then it goes to plastic buckling. At a thickness of $0.2 \mathrm{~mm}$, the buckling load is about the same as the yield stress given in Table 10.1 . With a thickness of $t=0.25 \mathrm{~mm}$, the window yields before it buckles. Substituting the height $a=1 \mathrm{~cm}$, window width $\mathrm{b}=8 \mathrm{~cm}$ into equation (12) (for the buckling stress of a rectangular plate with all edges clamped), yields:

$$
\sigma_{\mathrm{x}}=3.3 \mathrm{Et} 2=662 \mathrm{MPa} \text {, }
$$

which agrees very well with the finite element result of $317 \mathrm{MPa} * 1.63=516 \mathrm{MPa}$.

Table 10.3 is a list of the calculated maximum absolute $\sigma x$ and $\sigma y$ stresses, von Mises stress, and buckling factor. Figures 10.7 to 10.9 show the typical stress contours in a $300-\mu \mathrm{m}$ filter.

Table 10.3. Maximum $\sigma_{x} \sigma_{y}$ and Mises Stress

\begin{tabular}{ccccc}
$\begin{array}{c}\text { Filter thickness } \\
(\mu \mathrm{m})\end{array}$ & $\begin{array}{c}\text { Maximum } \sigma_{\mathbf{x}} \\
(\mathrm{MPa})\end{array}$ & $\begin{array}{c}\text { Maximum } \sigma \mathrm{y} \\
(\mathrm{MPa})\end{array}$ & $\begin{array}{c}\text { Maximum } \sigma \\
(\mathrm{MPa})\end{array}$ & Buckling factor \\
\hline 100 & -654 & -586 & 634 & 1.06 \\
200 & -410 & -370 & 400 & 1.29 \\
300 & -326 & -293 & 317 & 1.63 \\
\hline
\end{tabular}

\section{Application of Failure Criteria to the Window}

The maximum temperature of the Be window is far below the melting temperature of the material and poses no outgassing problem at $217^{\circ} \mathrm{C}$. With a $300-\mu \mathrm{m}$ graphite filter, the maximum von Mises stress of the window is $317 \mathrm{MPa}$. Depending on the manufacturer specification, some Be materials have a yielding stress of $480 \mathrm{MPa}$, while some can be as low as $206 \mathrm{MPa}$, as shown in Table 10.1. If a material has a yielding stress above $320 \mathrm{MPa}$, there is no low cycle fatigue problem for a $300-\mu \mathrm{m}$ graphite filter/250- $\mu \mathrm{m}$ Be windows design. The buckling load factor is 1.63 for this design. 
In summary, for APS wigglers, at least a 300- $\mu \mathrm{m}$ graphite filter is needed for the safety of two $250-\mu \mathrm{m}$ Be windows under the condition that the minimum yielding stress for $\mathrm{Be}$ is no less than $320 \mathrm{MPa}$. When radiation cooling is used for the filter, the filter still remains safe.

\section{Window Design for APS Bending Magnet Front Ends}

Analysis of a $0.25-\mathrm{mm}$ Be window was performed based on the APS bending magnet with $300 \mathrm{~mA}$ current. The absorbed power is very small. Even when twice the absorbed power was imposed on the window, the maximum temperature is about $70^{\circ} \mathrm{C}$, and the temperature increment on the window is $30^{\circ} \mathrm{C}$. The corresponding thermal stress shows that the maximum compression stress is only about $106 \mathrm{MPa}$, and the maximum von Mises stress is $95 \mathrm{MPa}$. Both are far below the yielding stress and the buckling stress. APS bending magnet front ends can function with a single Be window and require no filter.

\section{Conclusions and Suggestions}

1. Multi-failure criteria with different safety margins must be used to design and analyze the filter/window assembly.

2. Radiation cooling is preferred to conduction cooling for the filter.

3. From a structural point of view, the thicker the filter/window, the smaller the stresses in the structure.

4. If a filter is used with a Be window and the filter is thick enough, the maximum temperature of the window is almost constant and independent of the thickness of the window. An optimal thickness can be found by equating the buckling stress of the window with the yielding strength of the material.

5. When APS Undulator $A$ is operated at minimum gap size, the filter/window assembly will block a large fraction of low energy photons. However, when the gap size is equal to or larger than $1.5 \mathrm{~cm}$, at least $50 \%$ of the photons at first harmonic energy can pass through the filter/window assembly that satisfies all the failure criteria in Section 3.

6. APS Wiggler Alll can safely operate with a graphite filter/Be window assembly.

7. APS bending magnets do not require filters. A simple Be window is sufficient.

Suggestions can be made in the following areas. The postbuckling behavior of the window structure due to thermal load should be studied analytically and experimentally. A code for both wiggler and undulator power calculations should be available. 


\section{References}

1. Hideki Maezawa et al., Beryllium window and graphite filter assemblies for high heat flux synchrotron radiation beamlines at the Photon Factory, SPIE's 92 International Symposium on Optical Applied Science and Engineering, San Diego, July 19 -24, 1992.

2. Q. Shen, M. J. Bedzyk, M. J. Keeffer, and W. Schidkamp, A heat transfer study of the beam line components in high power wiggler and undulator beam lines. Part II. Beryllium windows, Rev. Sci. Instrum., Vol. 60, pp. 1464-1467, 1989.

3. John Cerino and Robert Cronin, Beryllium windows for synchrotron radiation beam lines, IEEE Transactions on Nuclear Science, Vol. NS-26, No. 3, June 1979.

4. Seiji Asaoka, Hideki Maezawa, and Yukihide Kamiya, Experiment on direct irradiation of a beryllium window by undulator radiation, $\operatorname{Rev}$. Sci. Instrum. Vol. $63, \mathrm{pp}$ 473-476, 1992.

5. Eric L. Brodsky, The mechanical design of thin beryllium windows for synchrotron radiation, Nucl. Instrum. Methods in Phy. Res., A266, (1988) 358-361.

6. Ali M. Khounsary, P. James Viccaro, and Tuncer M. Kuzay, Filter and window assemblies for high power insertion device synchrotron radiation sources, SPIE proceedings, Vol. 1345 Advanced X-ray/EUV Radiation Sources and Application (1990).

7. Roger J. Dejus, Ali M. Khounsary et al., The PHOTON2 program for calculating power densities and spectral flux from wigglers and its absorption in media, APS LSNote, Argonne National Lab., April 1992.

8. Gabriel J. DeSalvo and Robert W. Gorman, ANSYS Engineering Analysis System User's Manual, May, 1989.

9. Zhibi Wang, Automatic ID heat load generation in ANSYS code, APS LS-Note \#195, Argonne National Lab., May 1992.

10. Roger J. Dejus, Ali M. Khounsary, Barry Lai, and P. J. Viccaro, Absorption of Undulator Beams in Media, SPIE's 92 International Symposium on Optical Applied Science and Engineering, San Diego, July $19-24,1992$. 1961.

11.S. P. Timoshenko, Theory of Elastic Stability, 2nd Ed., McGraw-Hill Book Co.,

12. Zhibi Wang, Thermal and structural analyses of window assembly and comparison with experimental results, ANL Inter Laboratory Memo, Aug. 28, 1992.

13. Dave Brown, Experimental Verification of PHOTON2 and OEHL, Summer student report, Engineering \& Construction Group, XFD-APS, Argonne National Lab., Aug. 14, 1992. 
1992.

14. Users group, Optical elements heat load studies, SPring-8 Project Team, June,

15. U. Hahn, W. Graeff et al., The hard x-ray wiggler (HARWI) beamline at HASYLAB, Vaccum Design of Advanced and Compact Synchrotron Light Sources, American Institute of Phy. Conference Proceed., No 171, 1988.

16. G. K. Shenoy, P. J. Viccaro and D. M. Mills, Characteristics of the 7-GeV advanced photon source: a guide for users, ANL-88-9, Argonne National Lab., Feb. 1988.

17. Zhibi Wang, Thermal and structural analyses of graphite filter vs. Be filter, ANL Inter Laboratory Memo, Sept. 1992.

18. Zhibi Wang, SR power generation and graphic interface, ANL Inter Laboratory Memo, Nov. 1992.

19. Personnel communication with Dave Ryding, U. Hahn, 1992.

\section{Acknowledgment}

Thanks are due to D. Shu and S. Sharma. 


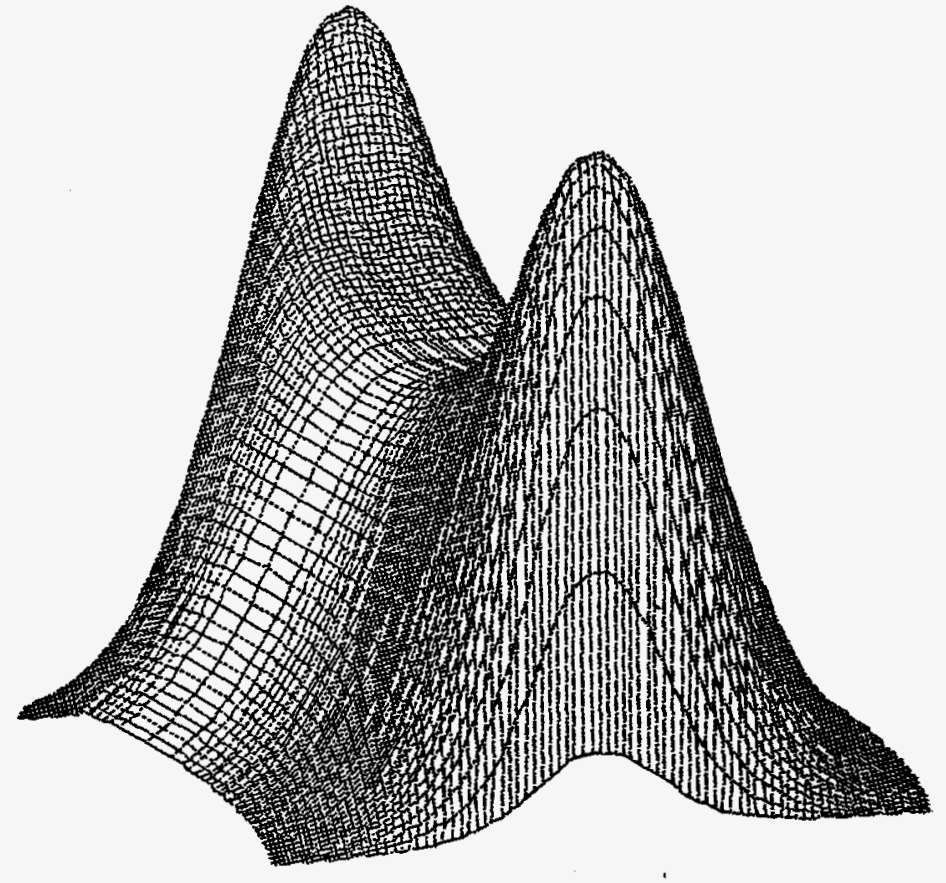

Figure 2.1. Surface representation of absorbed power on a filter

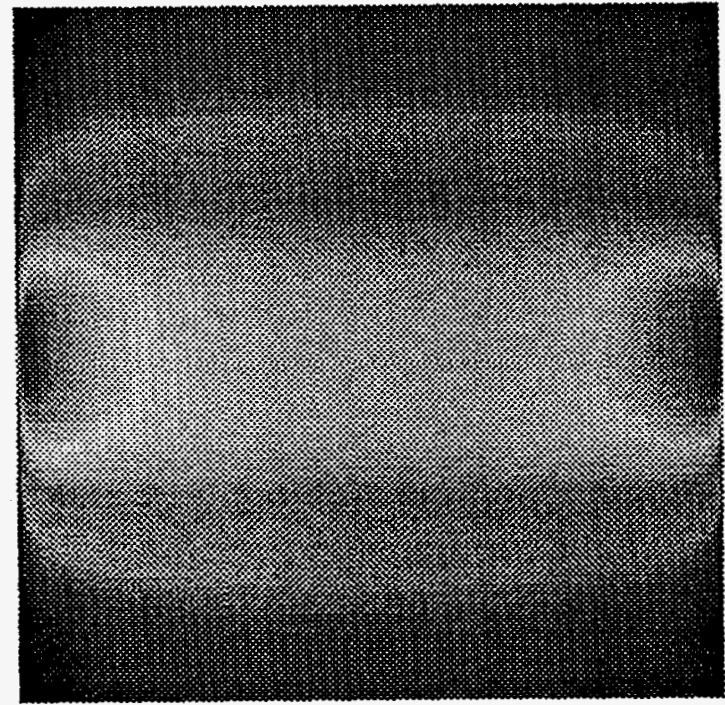

Figure 2.2. Contour representation of absorbed power on a filter 


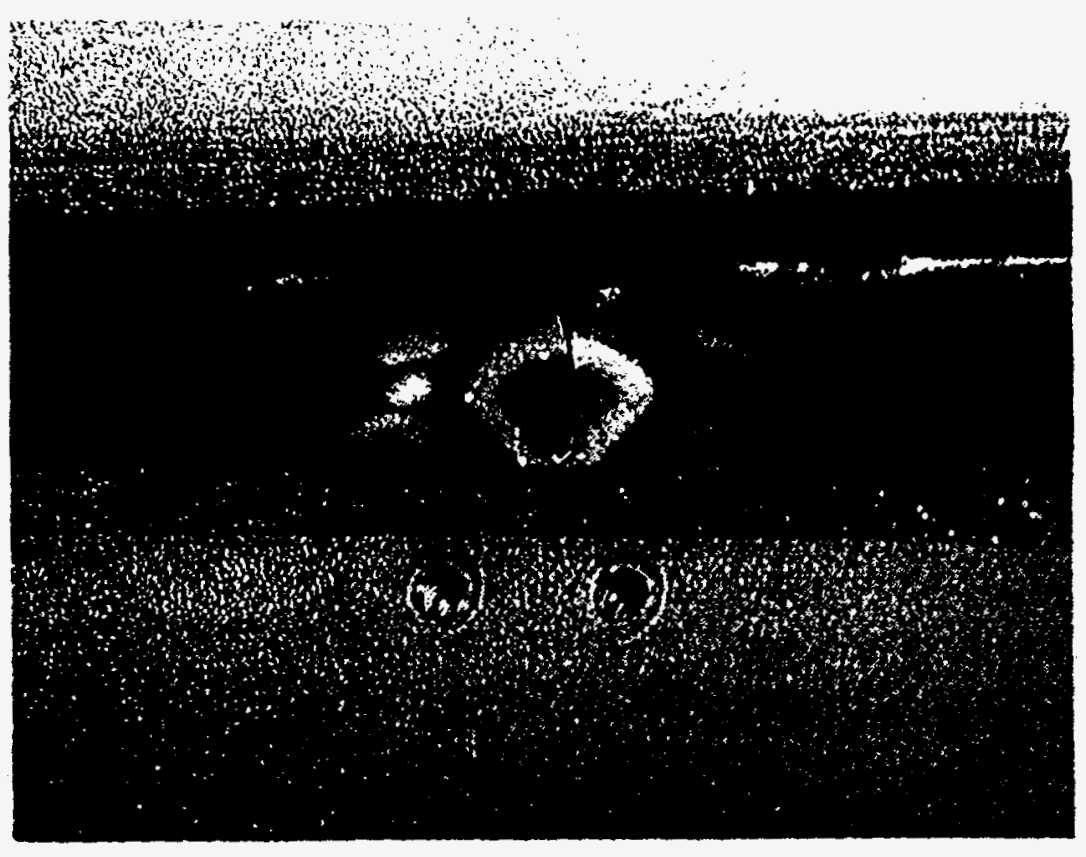

Figure 4.1. Window failure of test sample 1

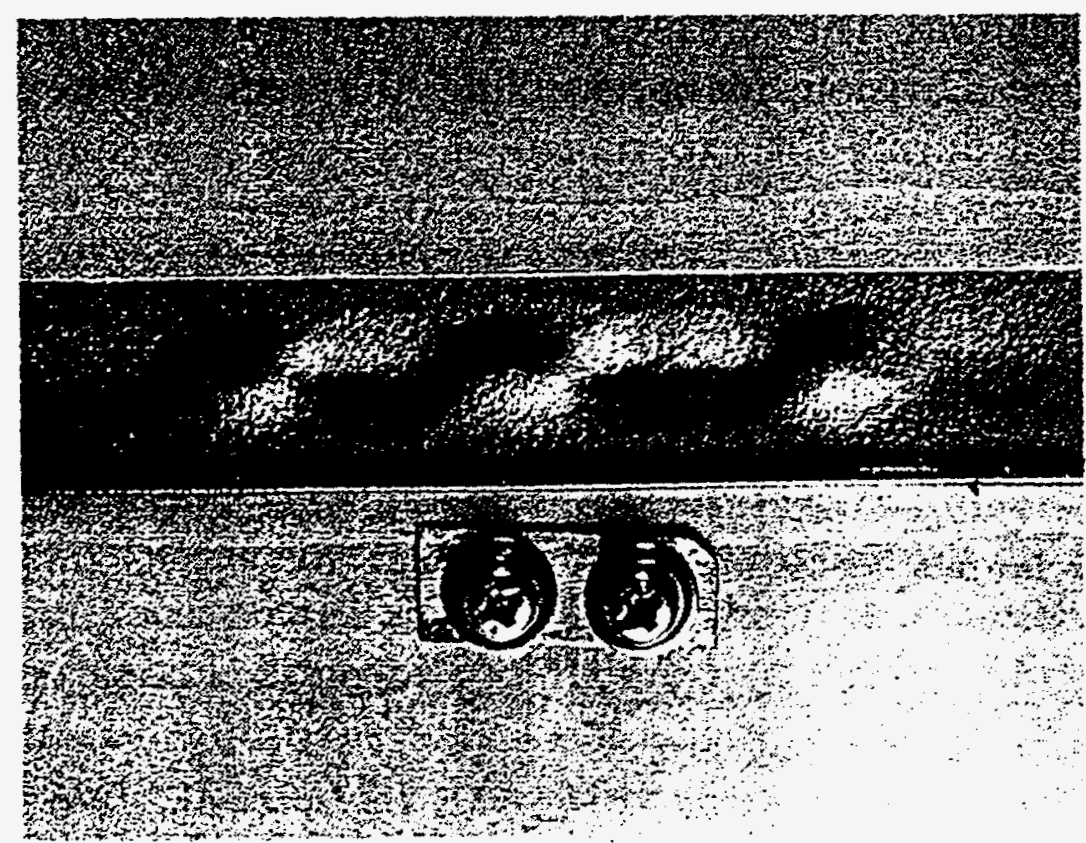

Figure 4.2. Window failure of test sample 2 


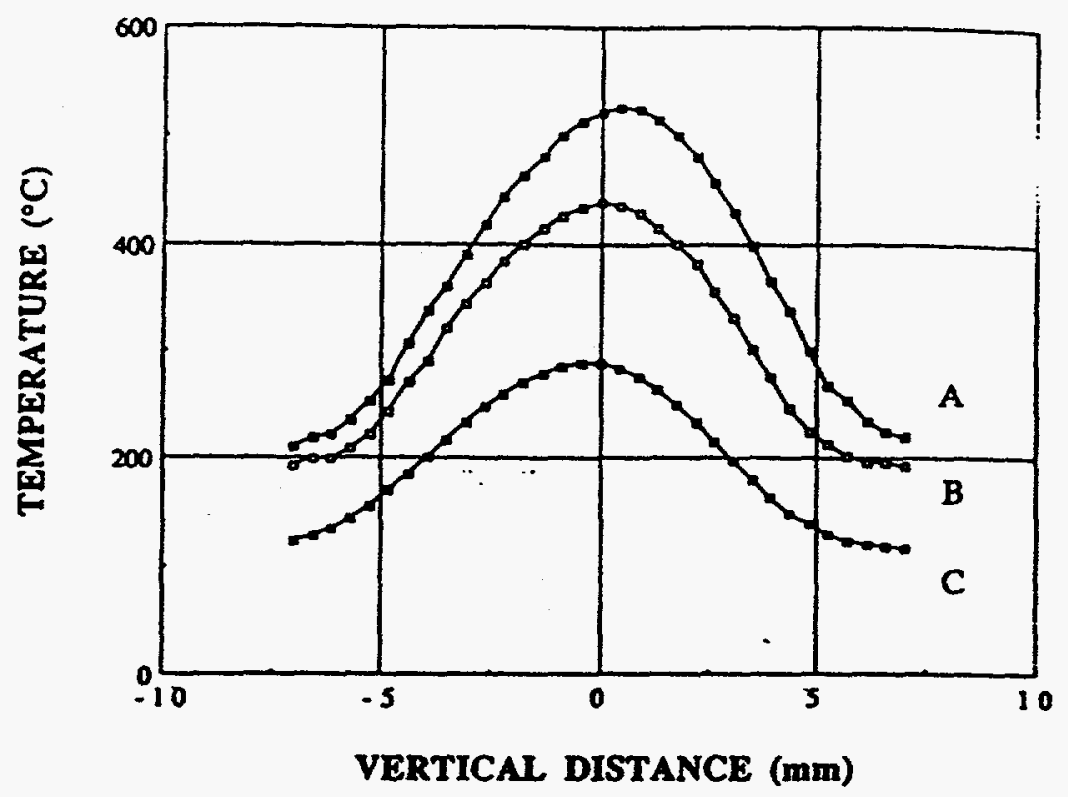

Figure 4.3. Temperature profile along vertical direction from tests

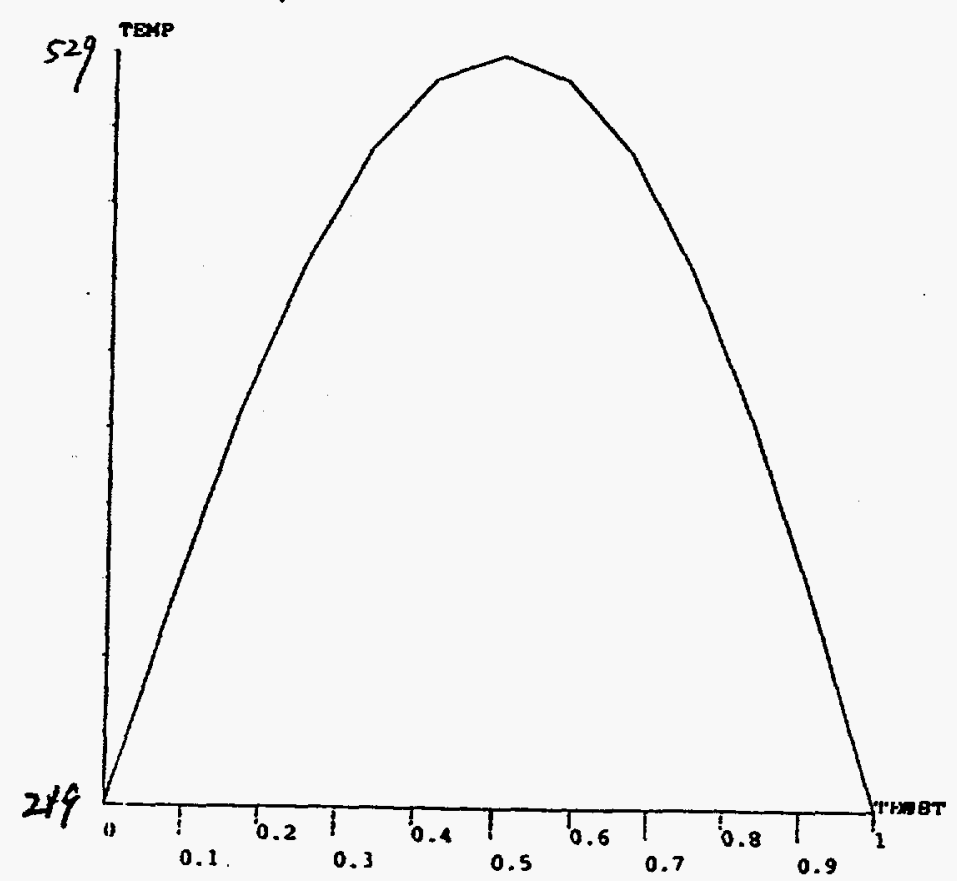

Figure 4.4. Temperature profile along vertical direction from analysis 


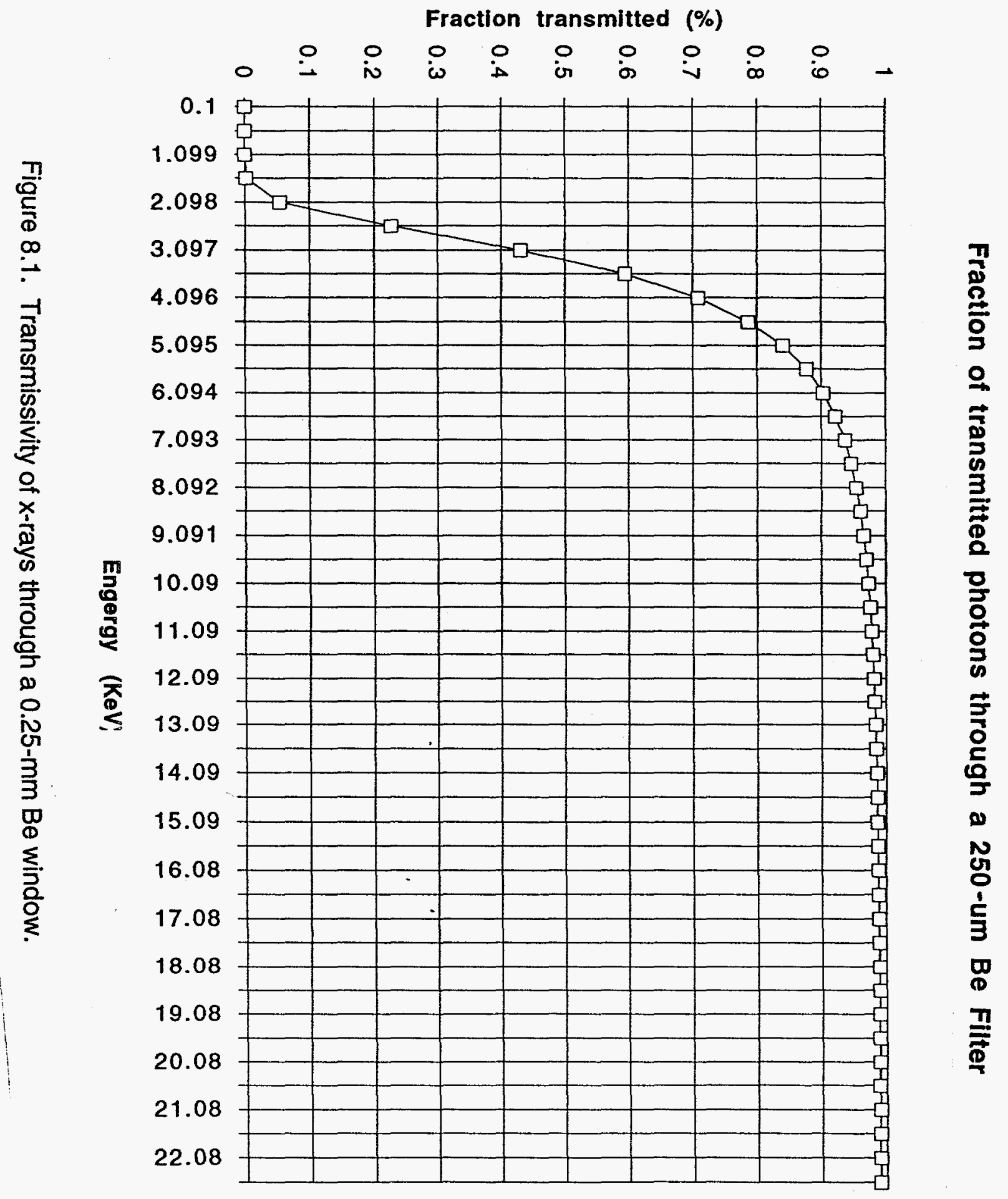




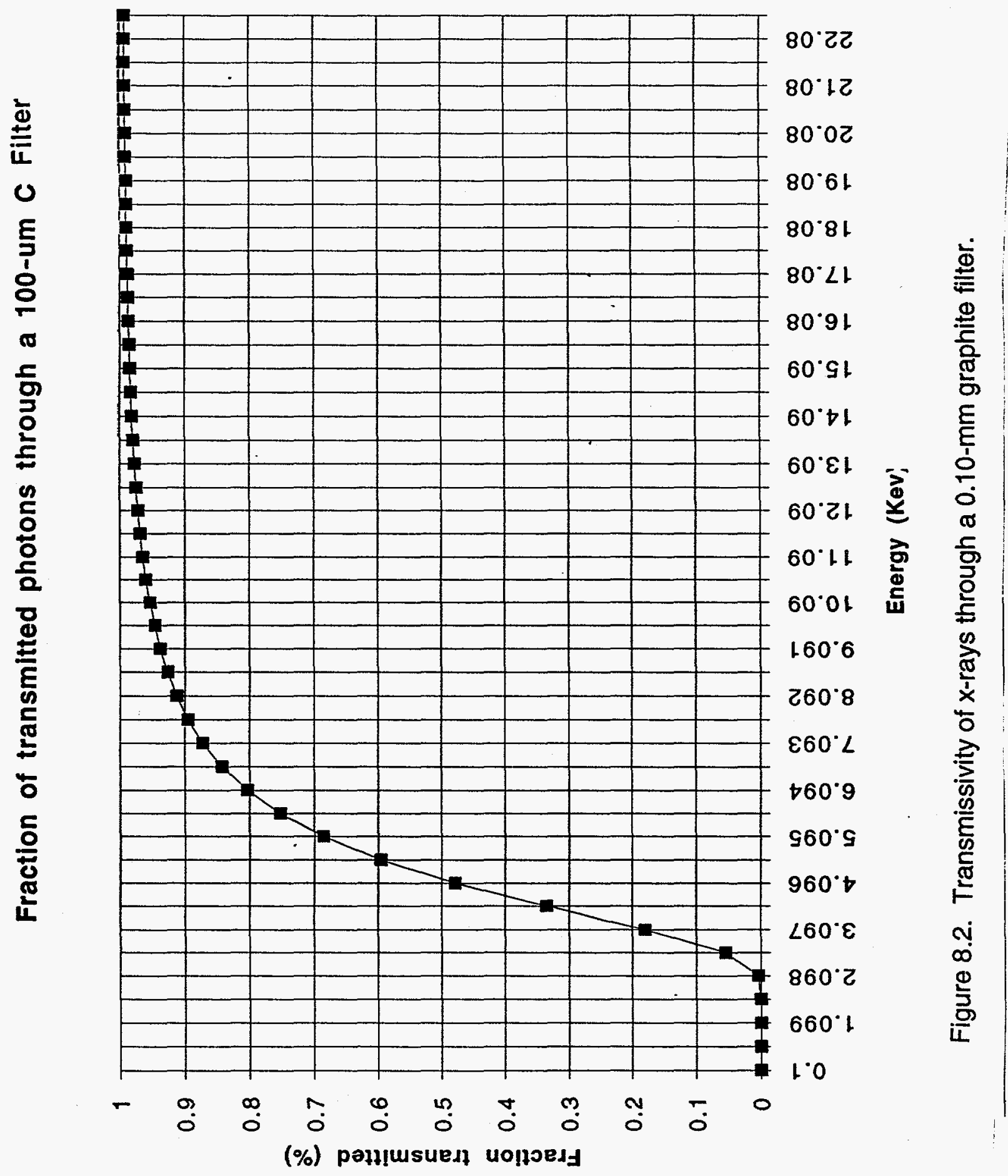




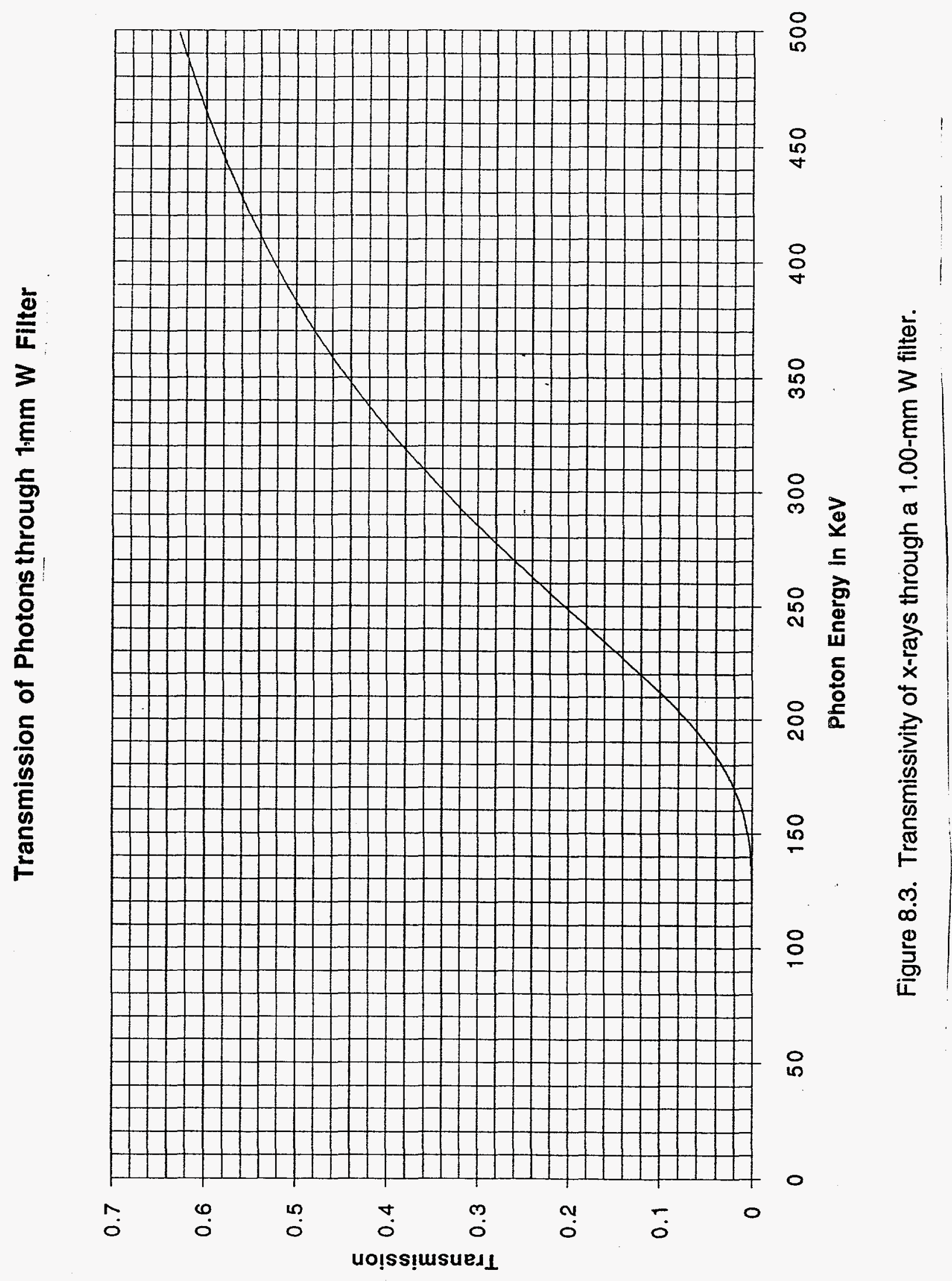









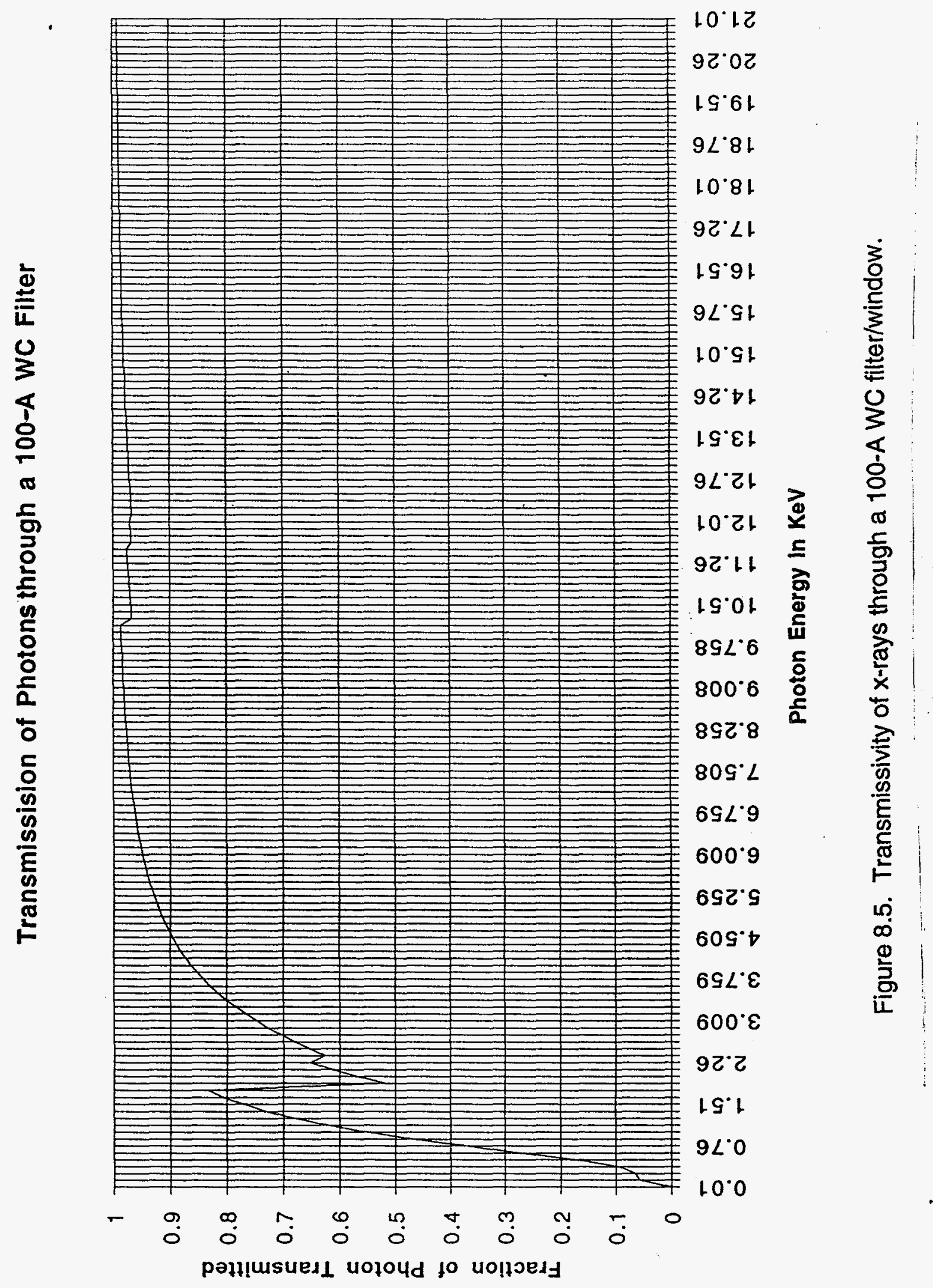




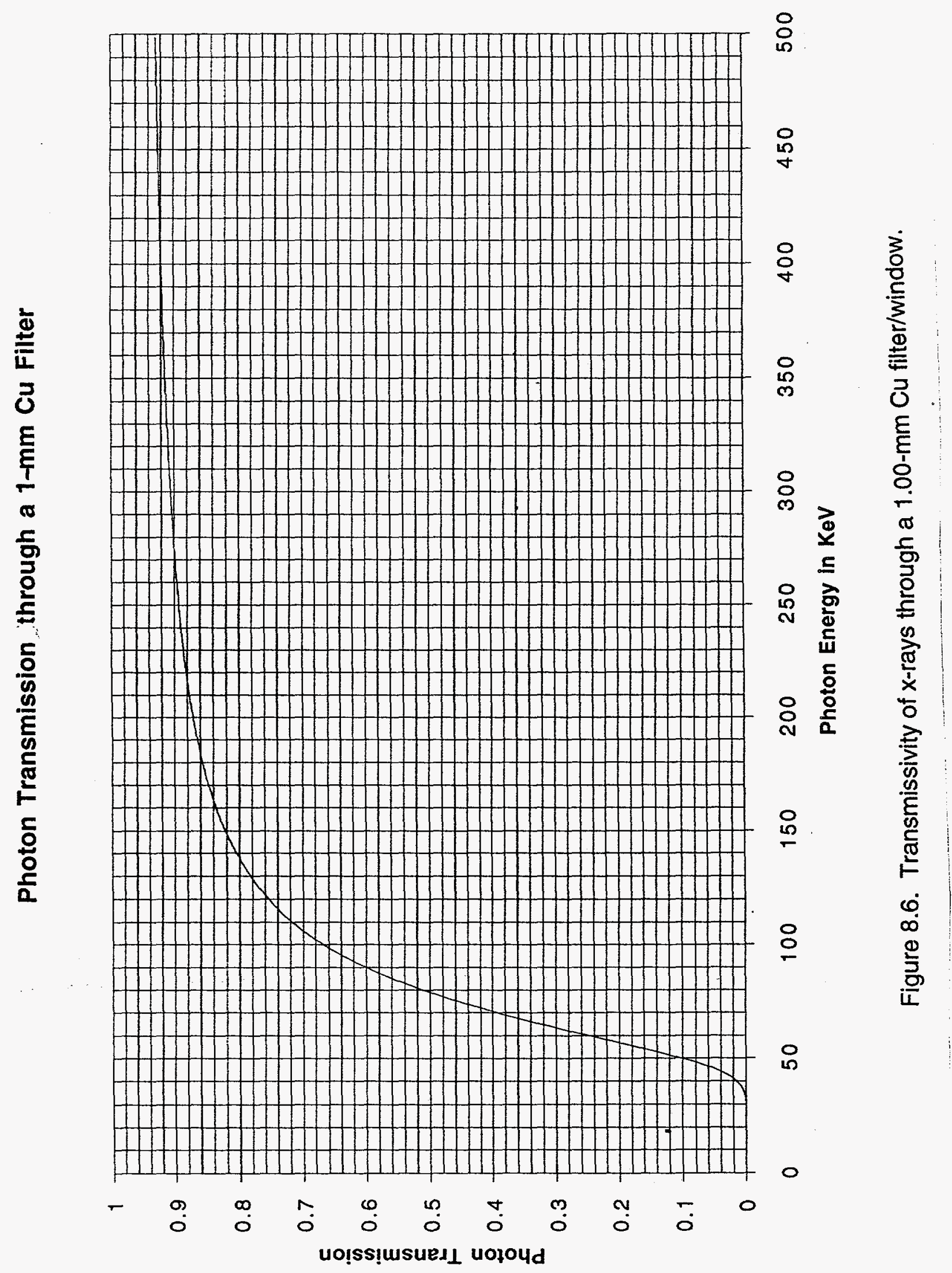




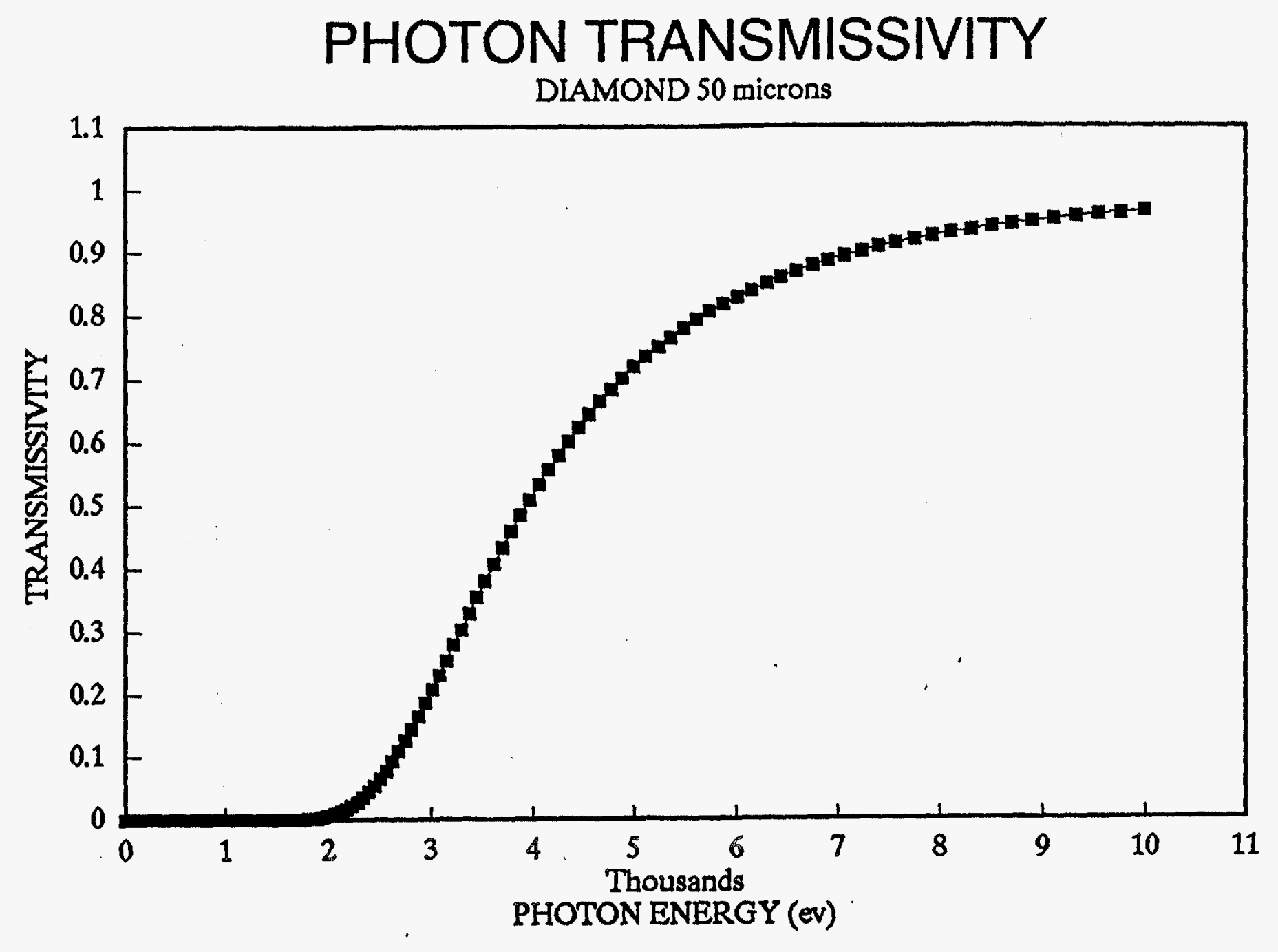

Figure 8.7. Transmissivity of $x$-rays through a 50- $\mu \mathrm{m}$ diamond filter/window. 


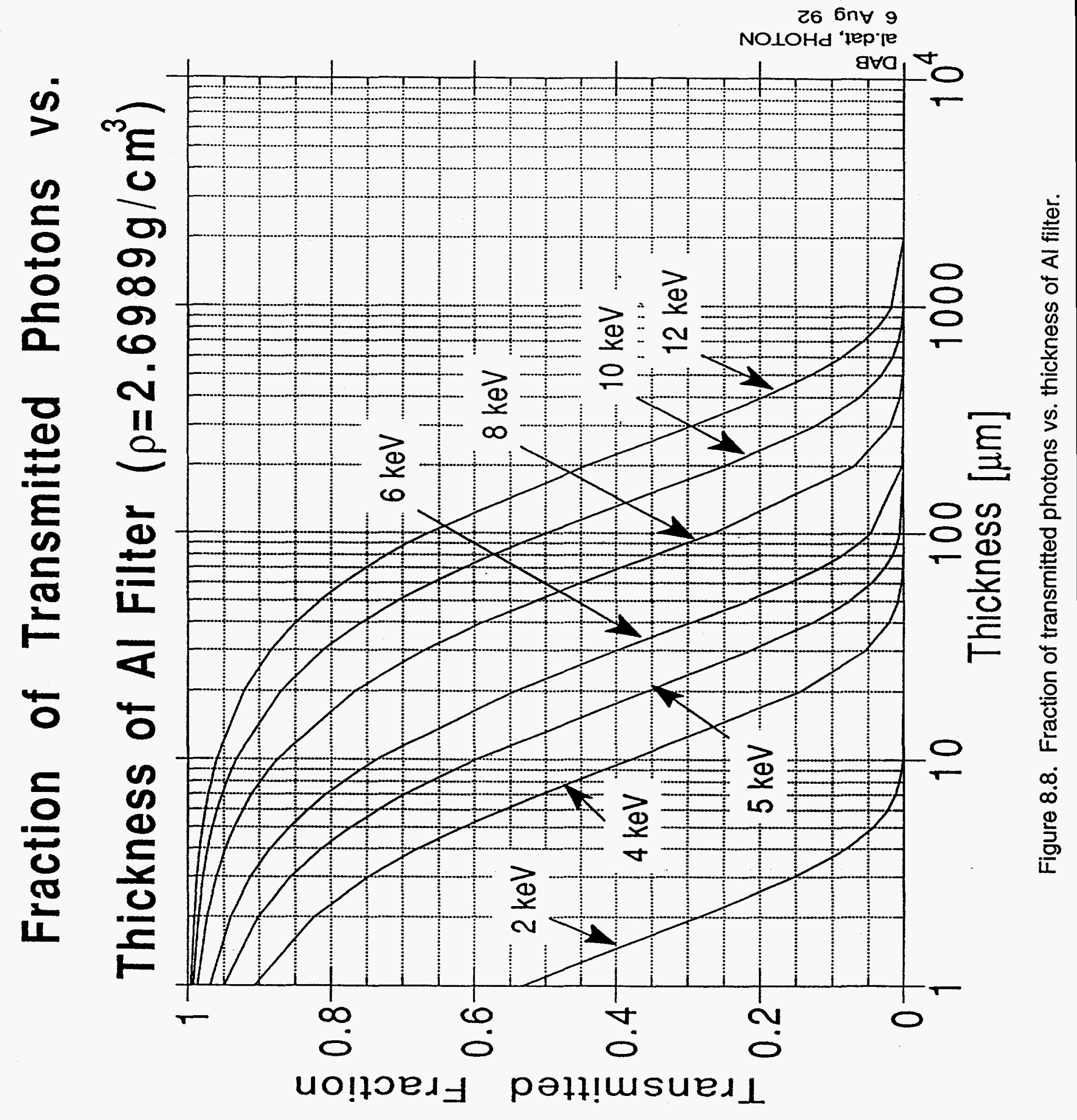




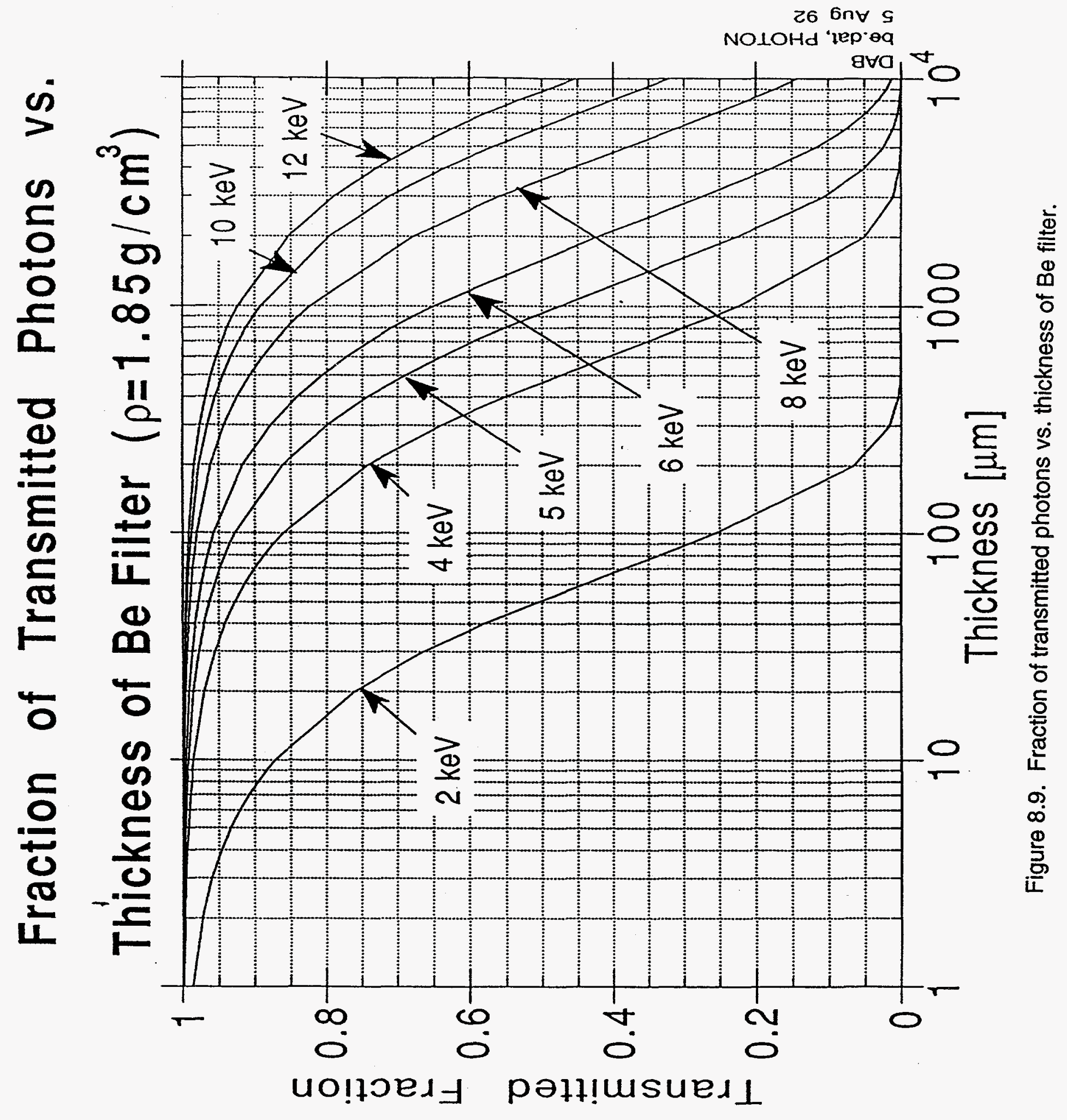




\section{Fraction of Transmitted Photons vs.}

\section{Thickness of Diamond Filter $\left(\rho=3.51 \mathrm{~g} / \mathrm{cm}^{3}\right)$}

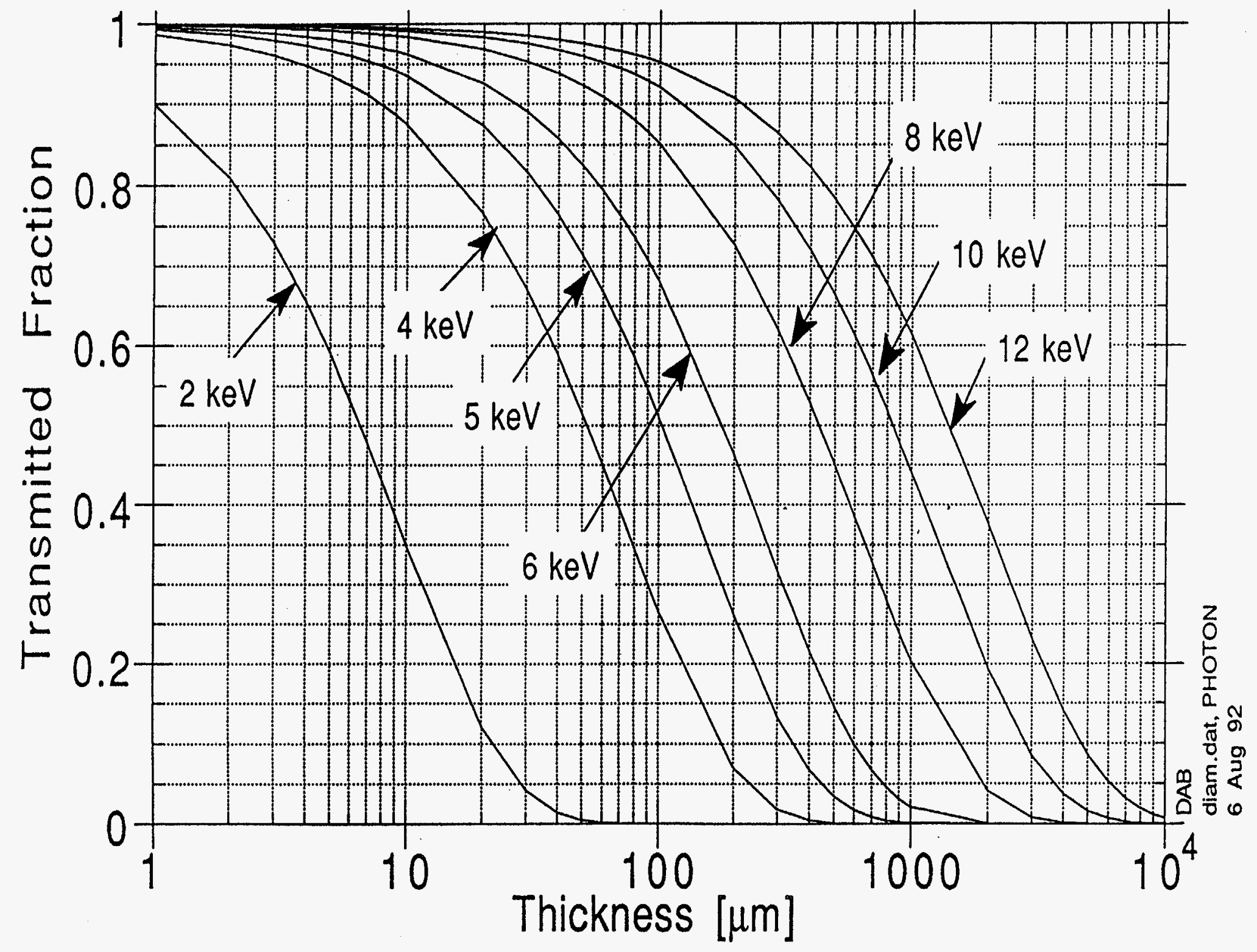

Figure 8.10. Fraction of transmitted photons vs. thickness of diamond filter. 
26 6nt 9

NOLOHA 'rep'o!s

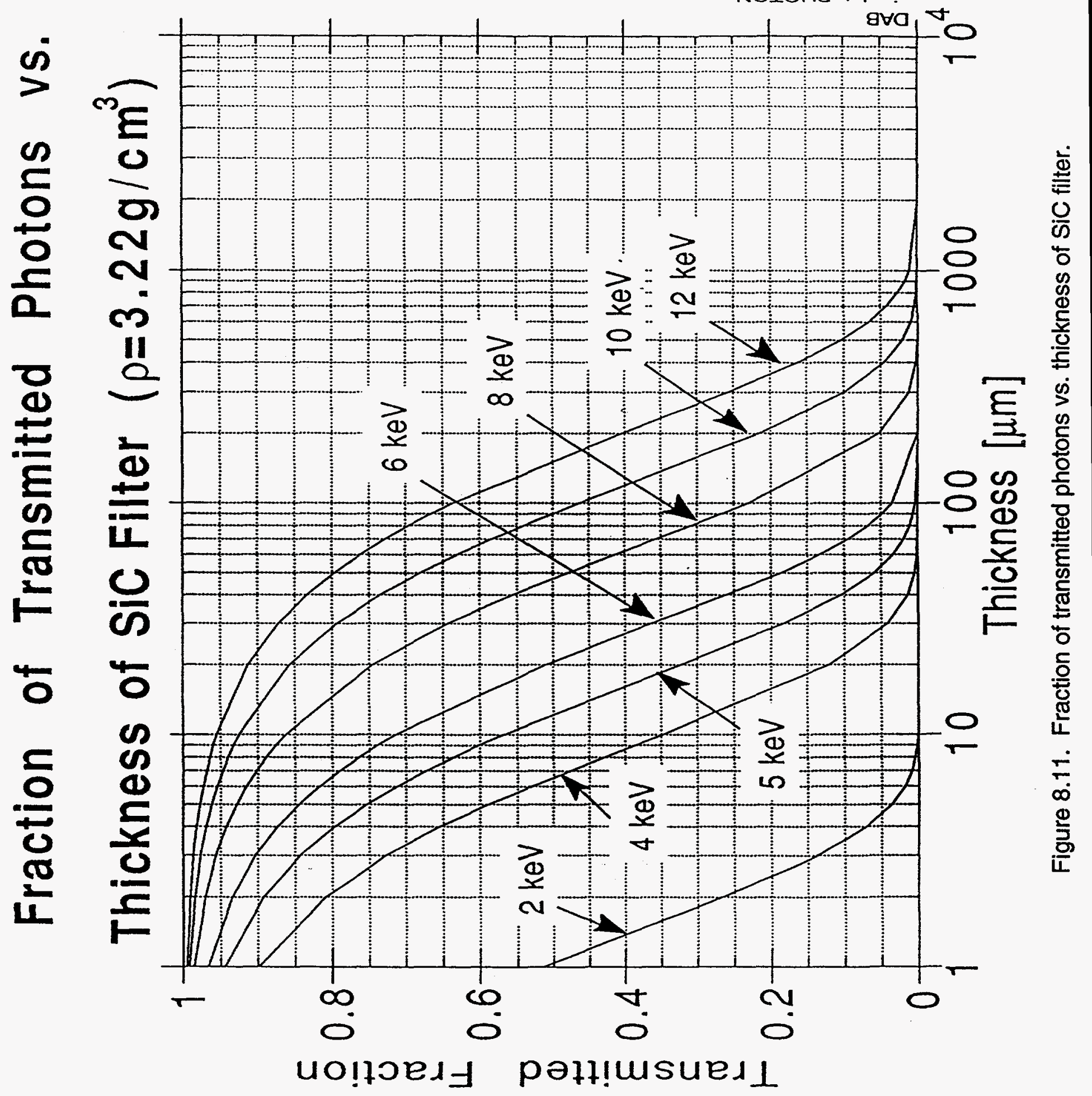


26 6nt 9

NOLOHd 'iep'uq

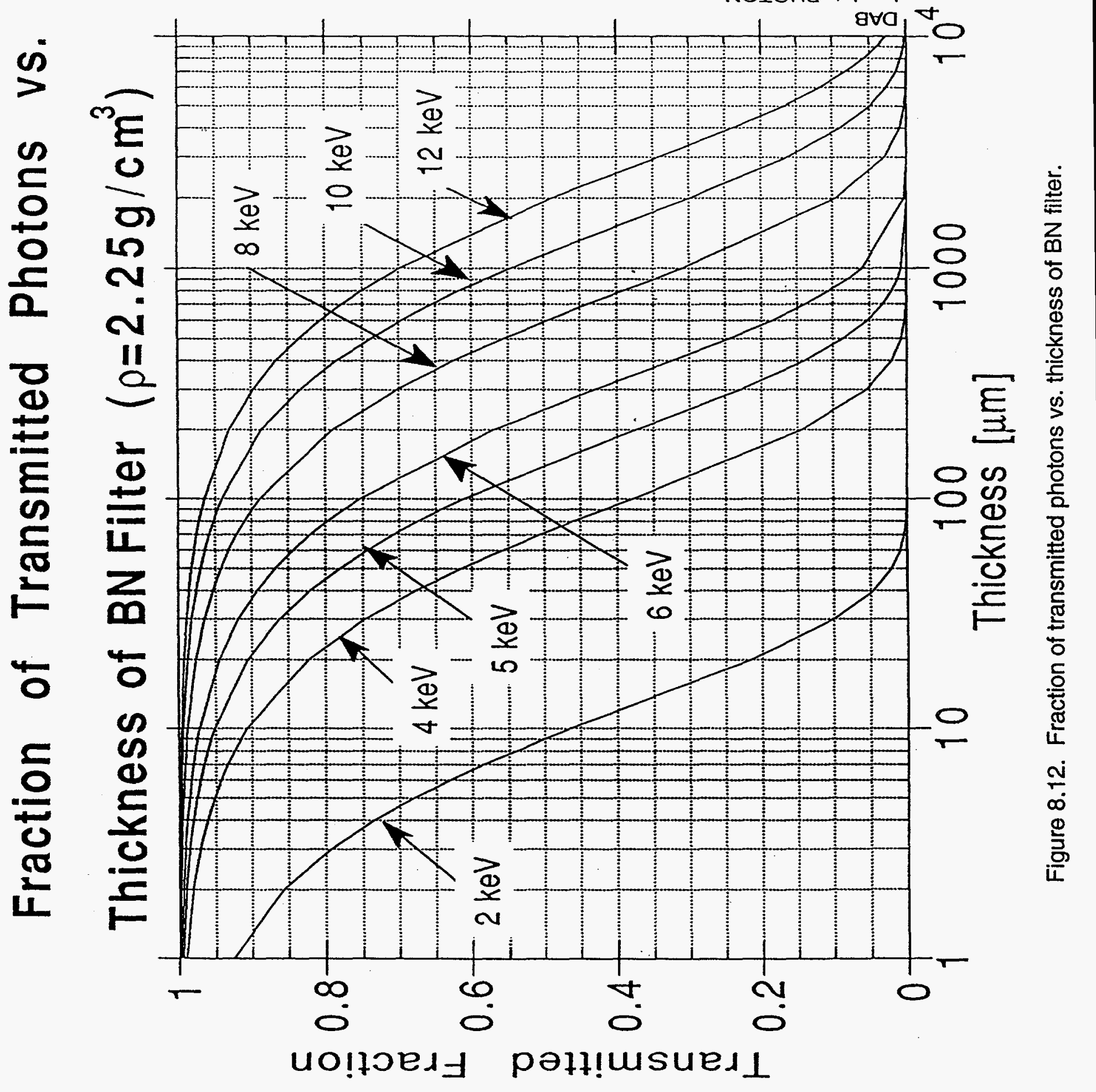




\section{Fraction of Transmitted Photons vs.}



Figure 8.13. Fraction of transmitted photons vs. thickness of Si filter. 


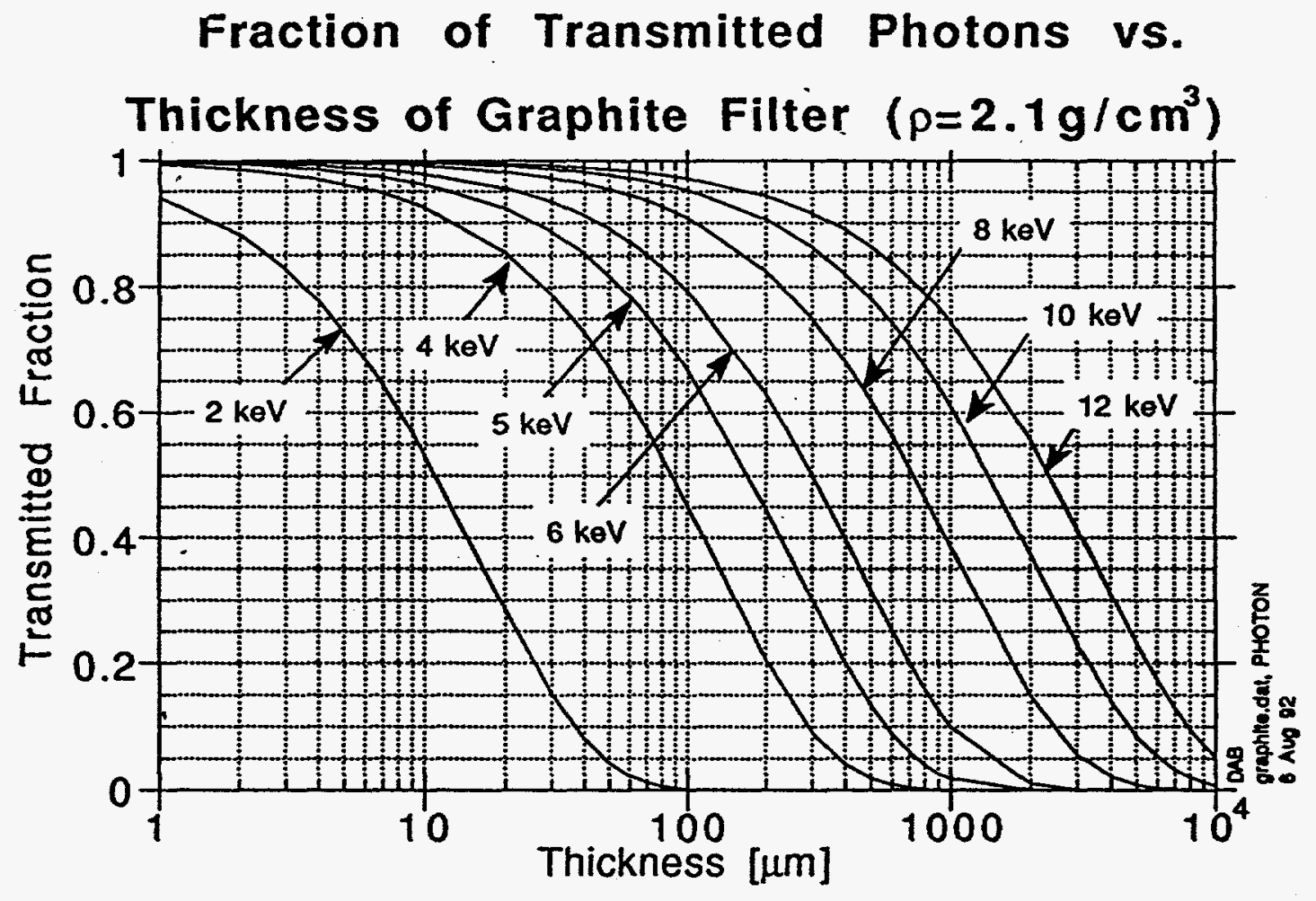

Figure 8.14. Fraction of transmitted photons vs. thickness of graphite filter. 


\section{Absorbed Power Density:}

- Blue surface (fine mesh): wiggler approximation

- Red surface (course mesh): Bessel function approximation

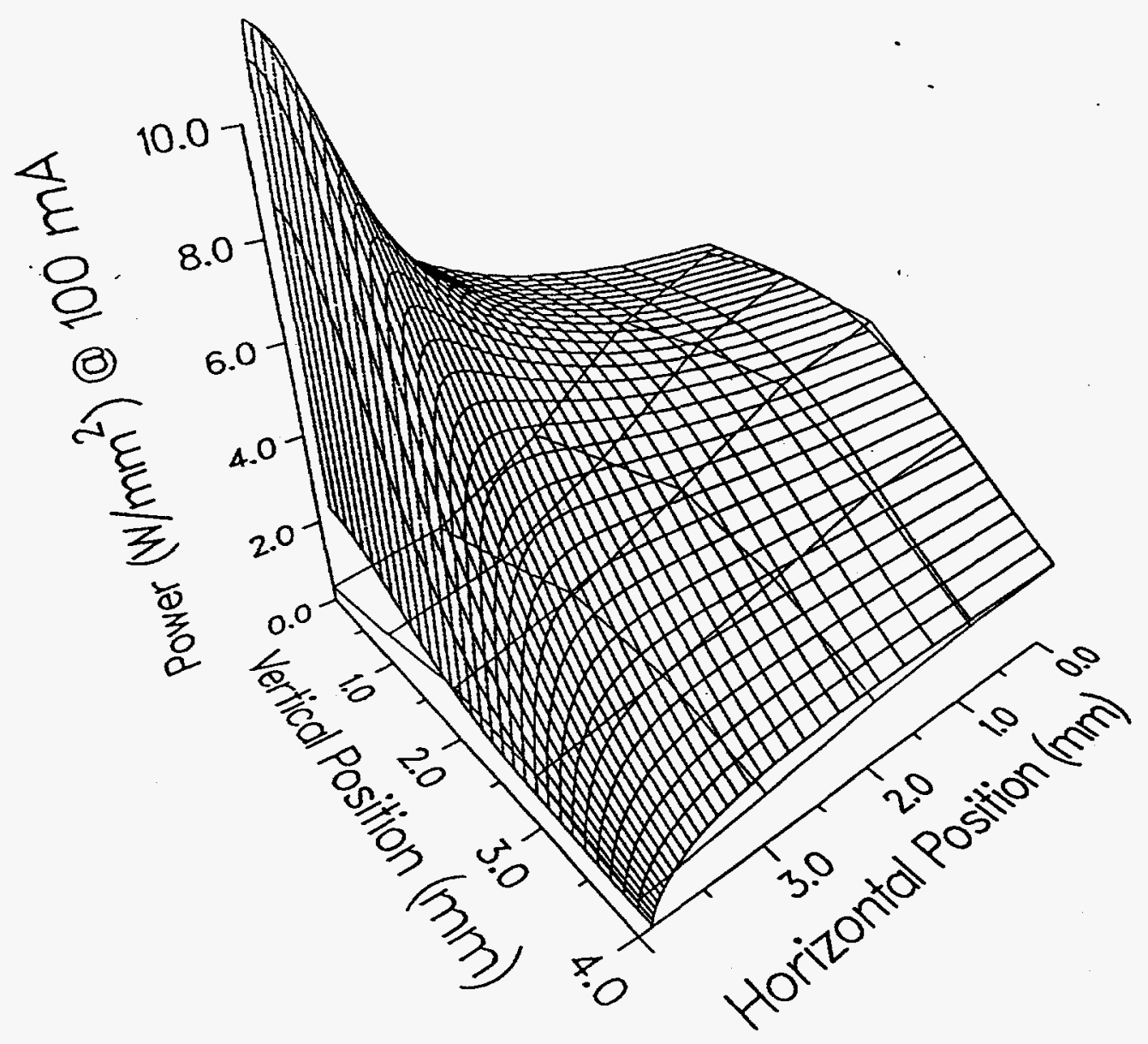

Figure 9.1. Comparison of absorbed power through a Be filter by wiggler approximation and Bessel function approximation. 


\section{Absorbed Power by PHOTON2 and US for UDA with $K=2.2$}

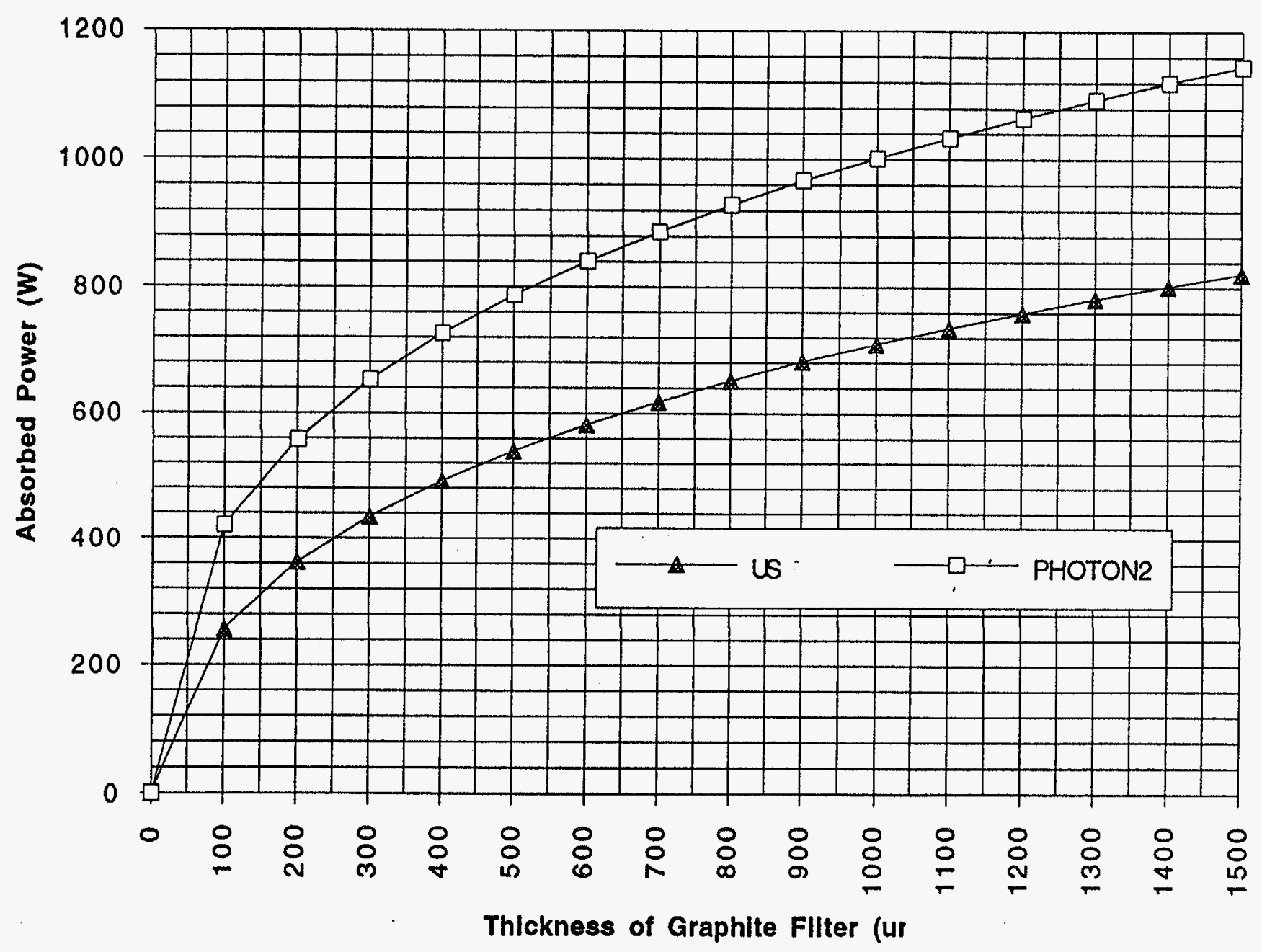

Figure 9.2. Comparison of the absorbed powers in graphite filter by wiggler approximation and Bessel function approximation. 


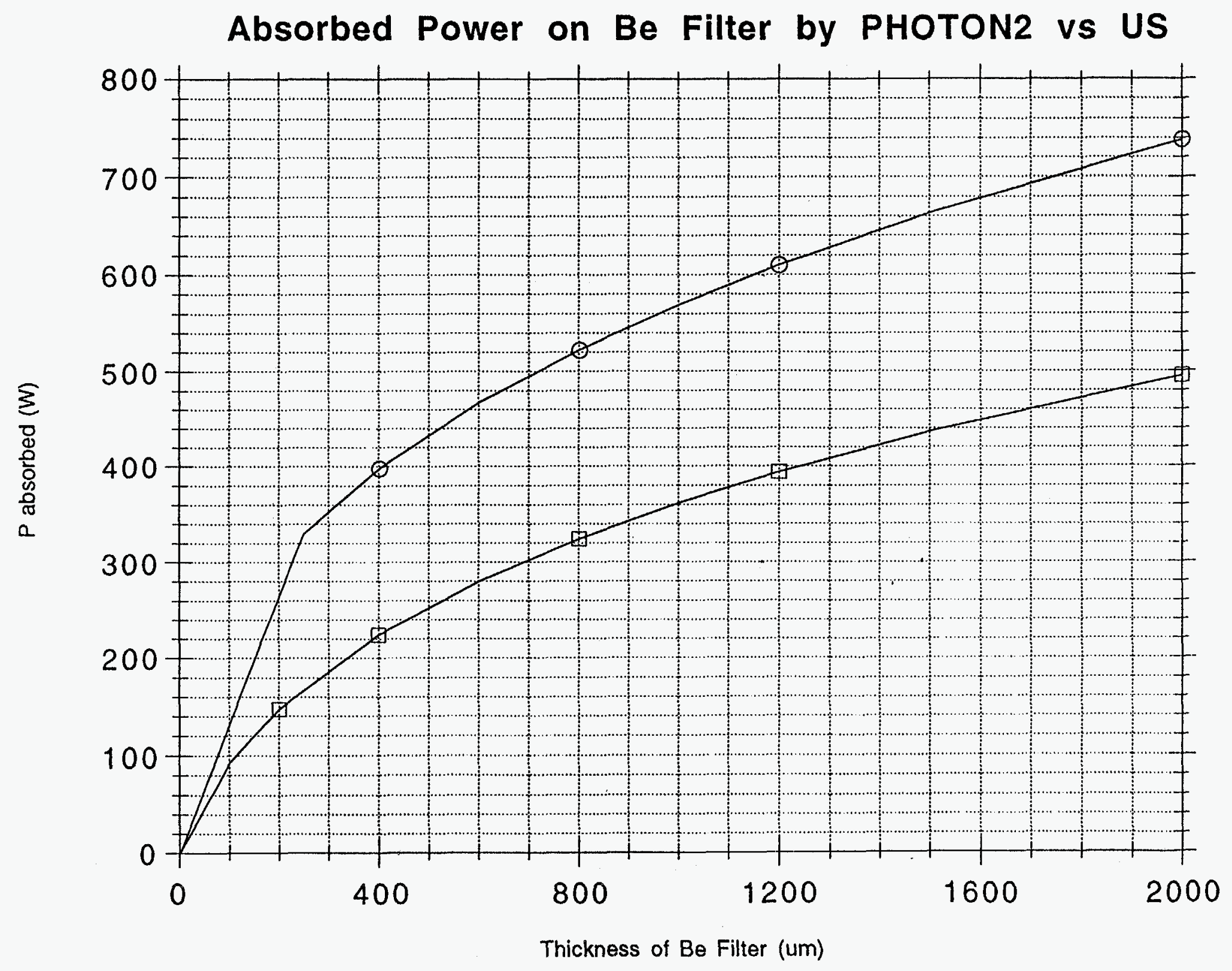

Figure 9.3. Comparison of the absorbed powers in Be filter by wiggler approximation and Bessel function approximation. 
(M) Mopu!M pue dәl!! u! dәMOd pequosq
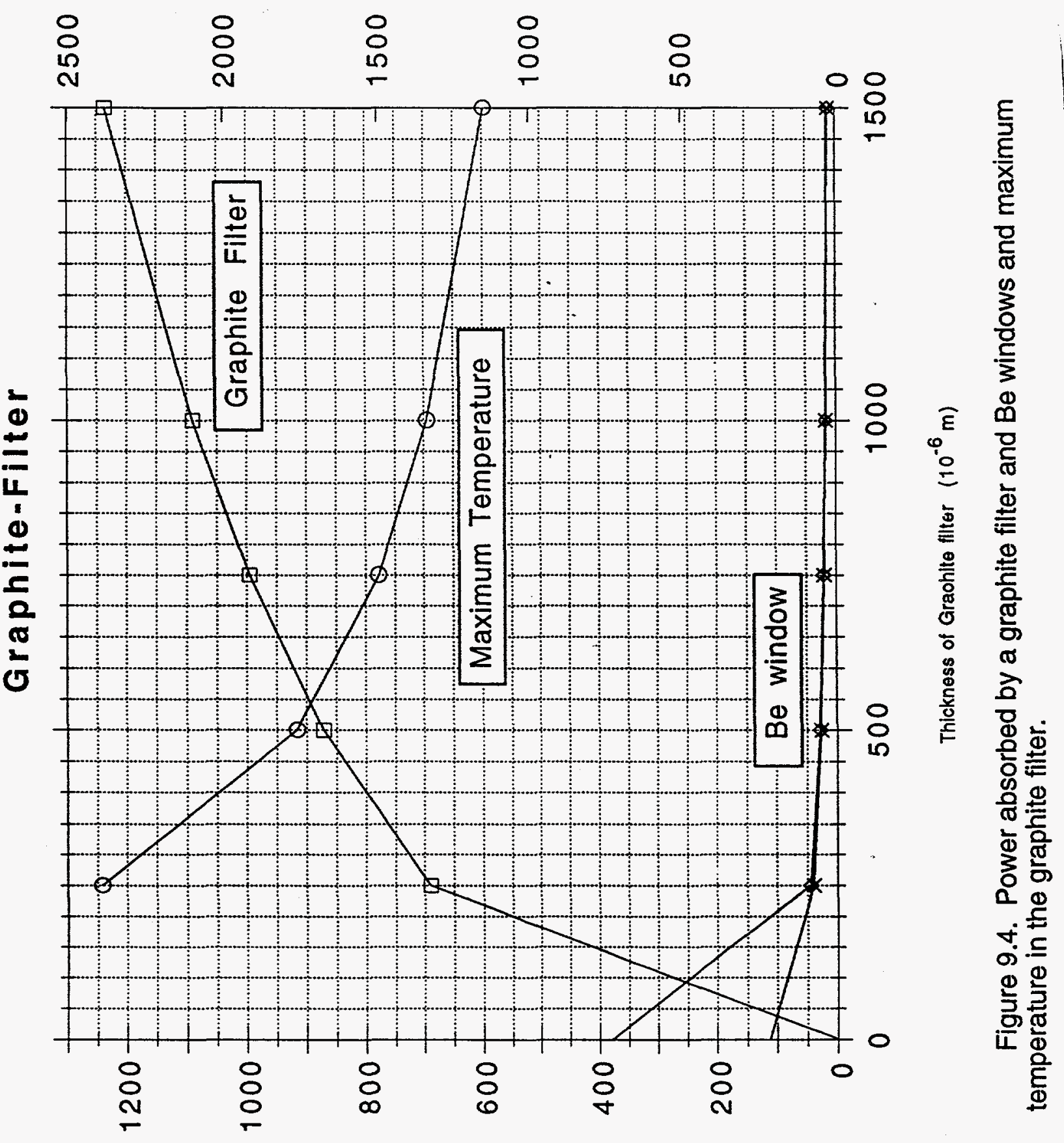

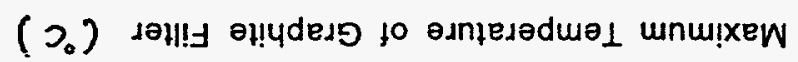




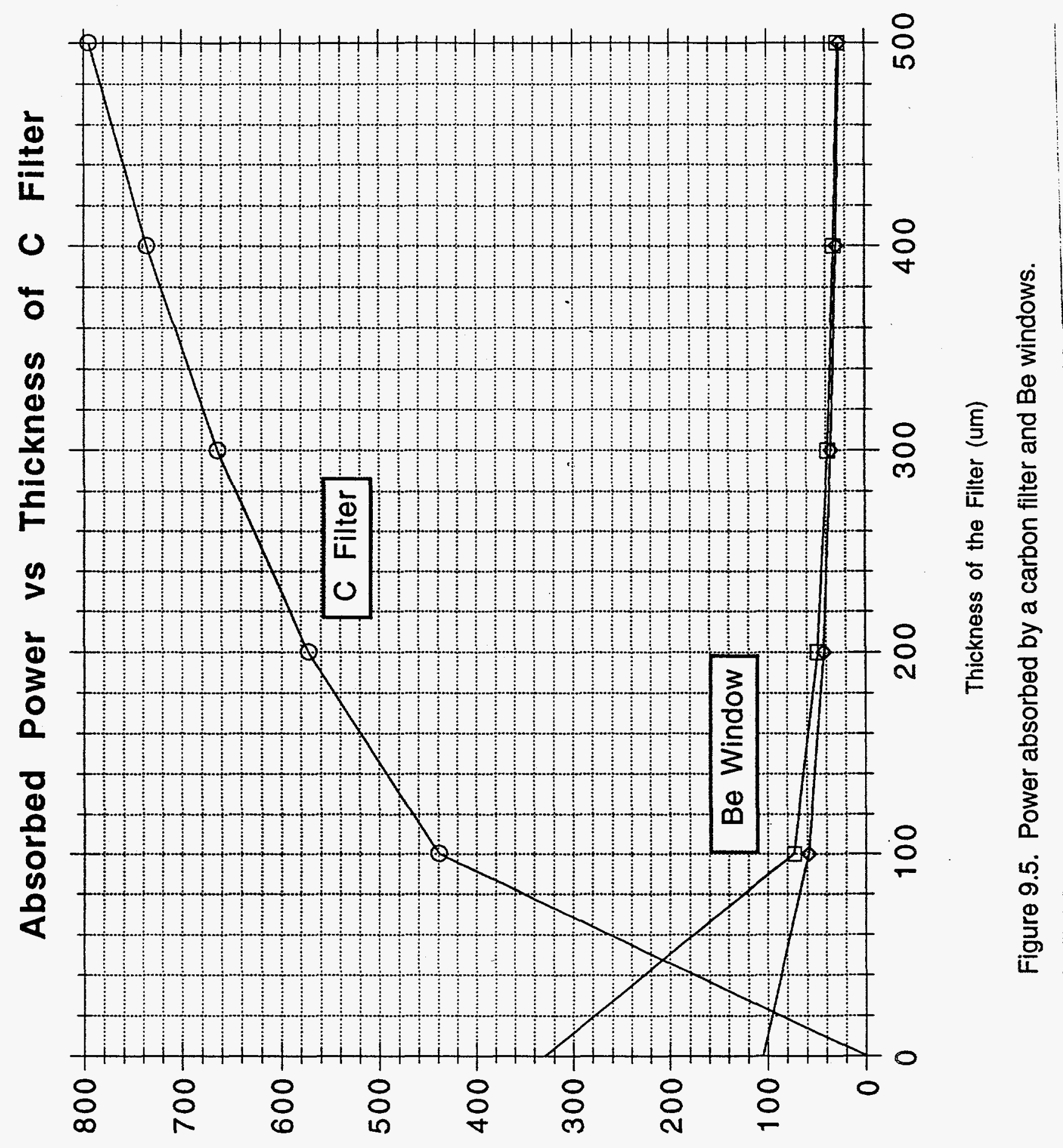




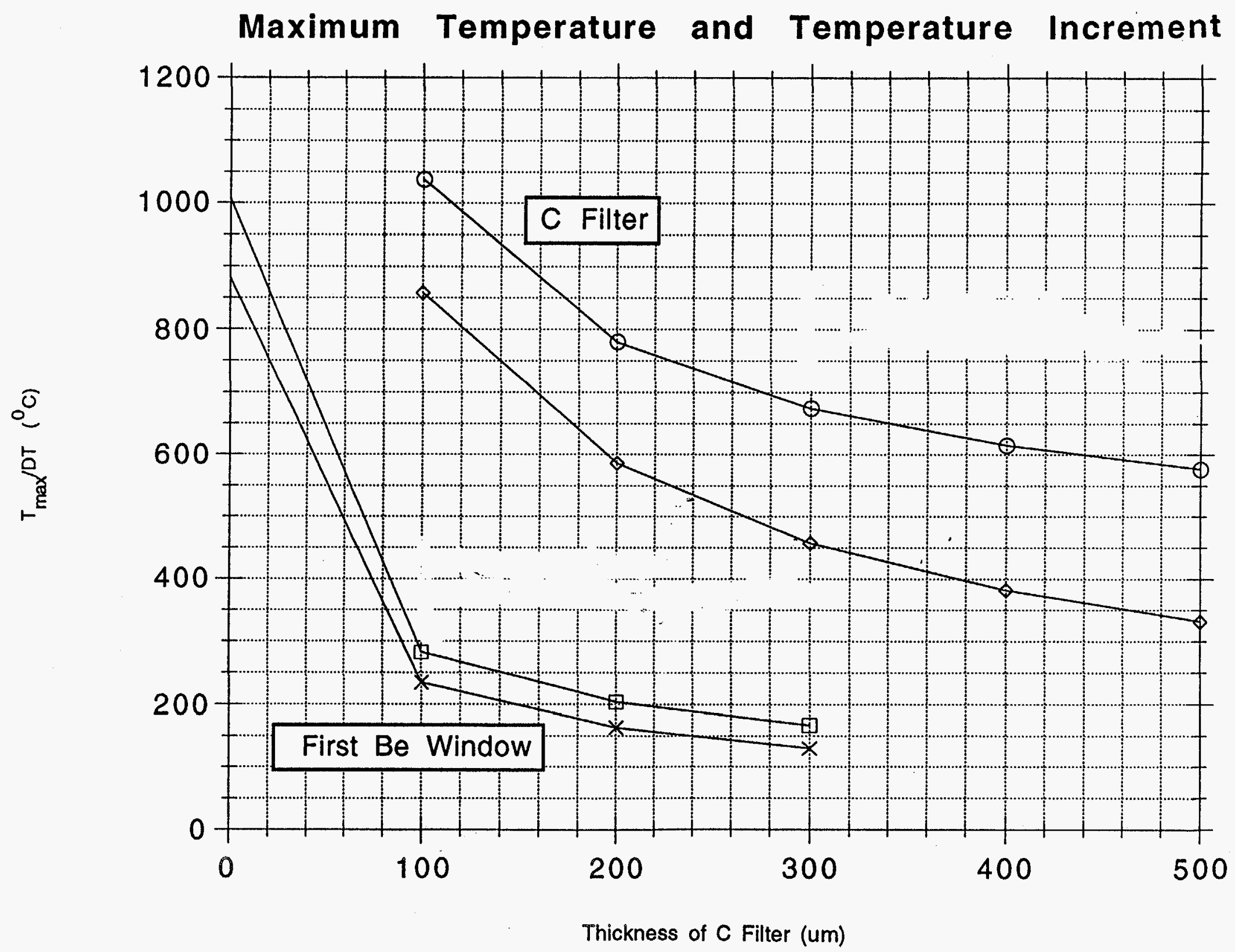

Figure 9.6 The maximum temperatures and temperature increments for the graphite filter and first $\mathrm{Be}$ window. 
Fraction of Transmitted Photon @ $5 \mathrm{KeV}$ (\%)

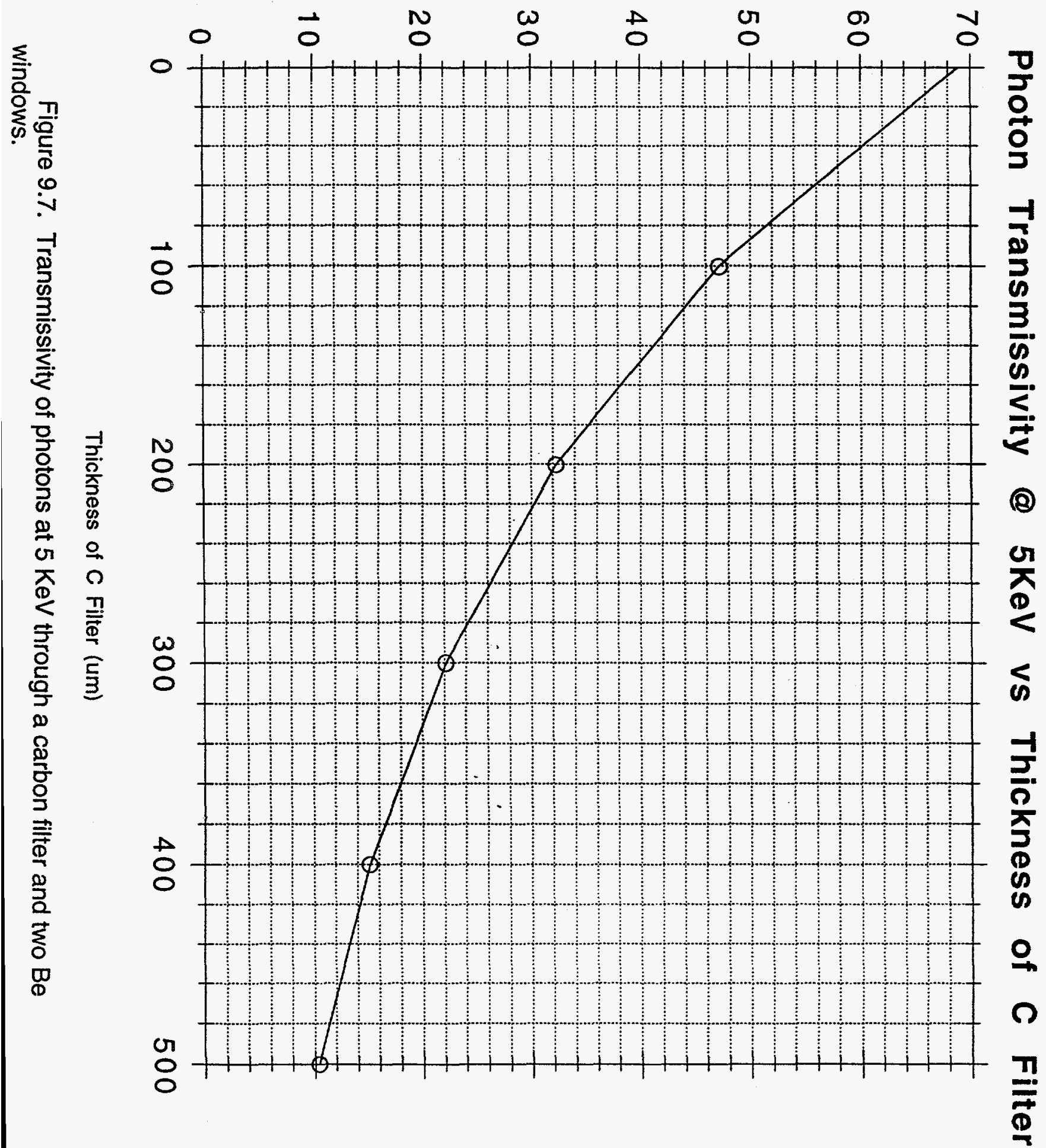




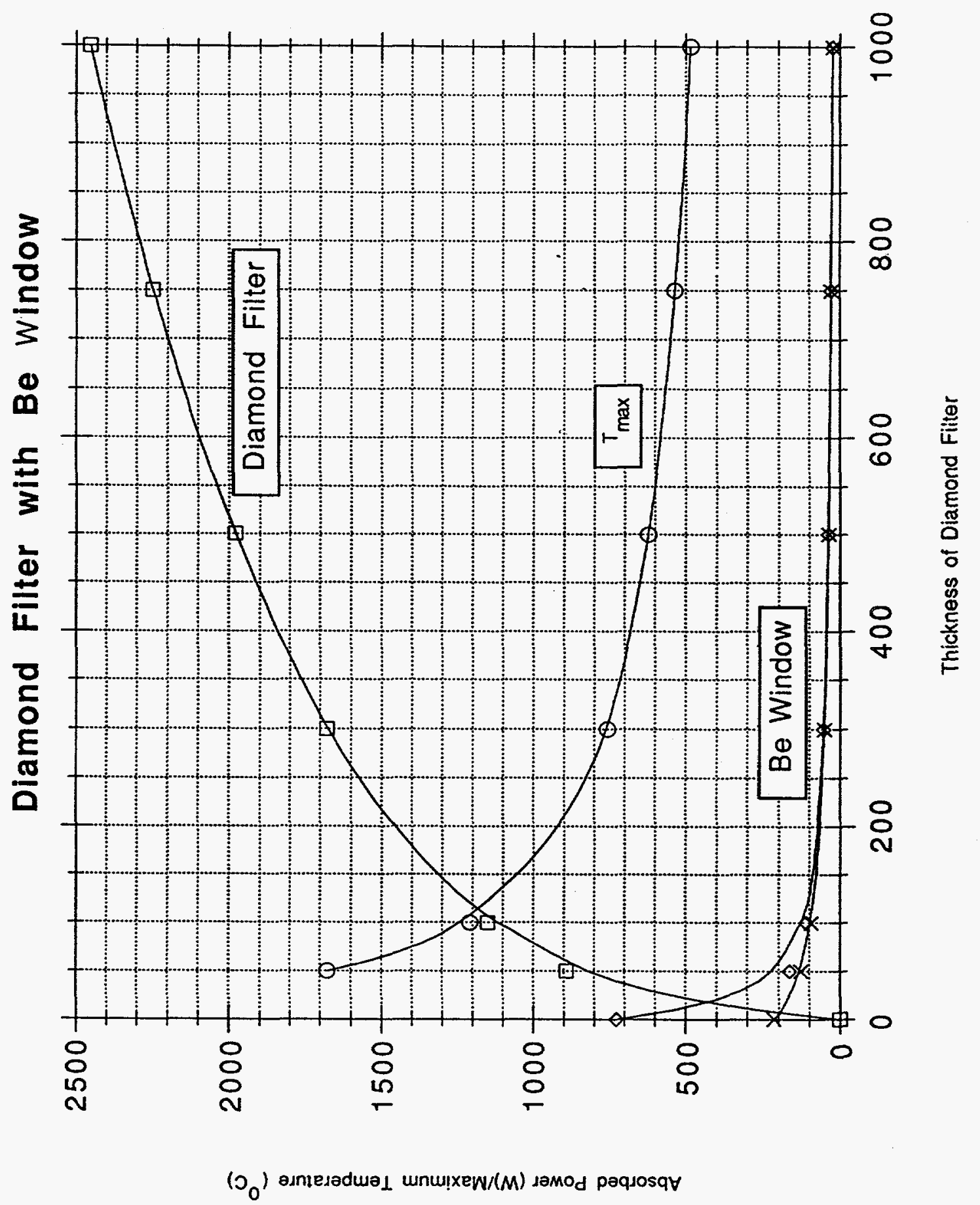

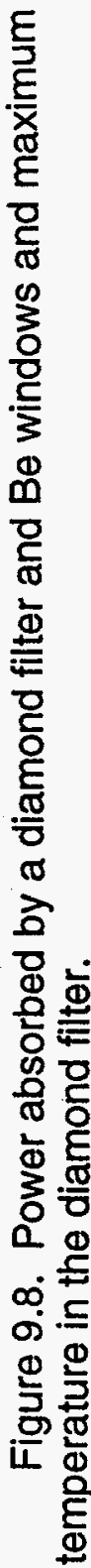




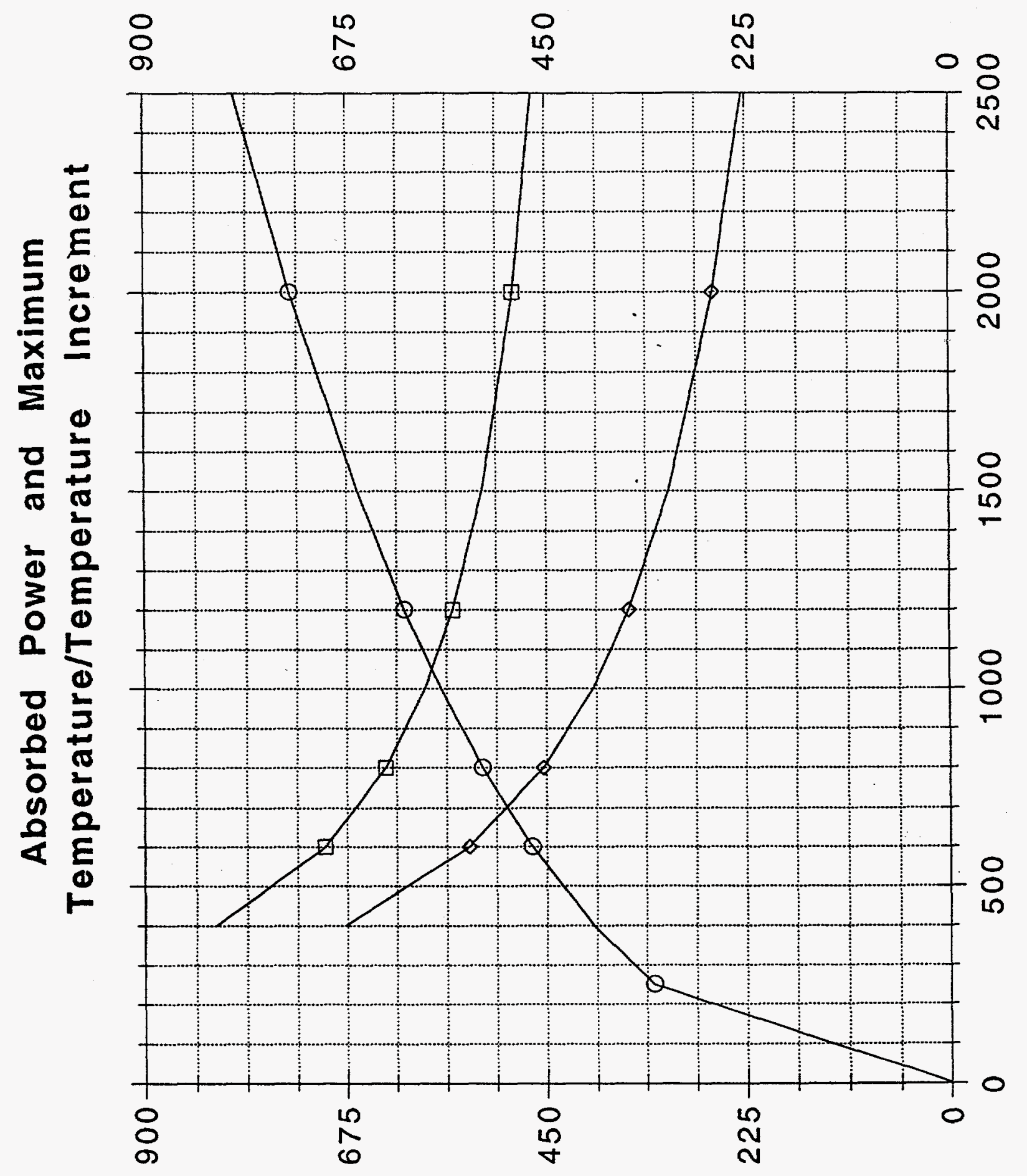

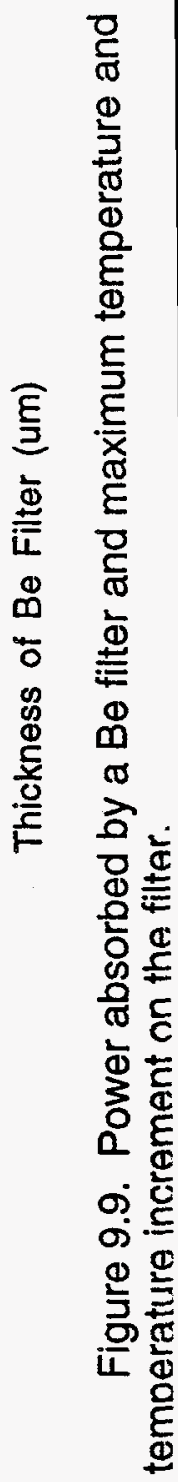




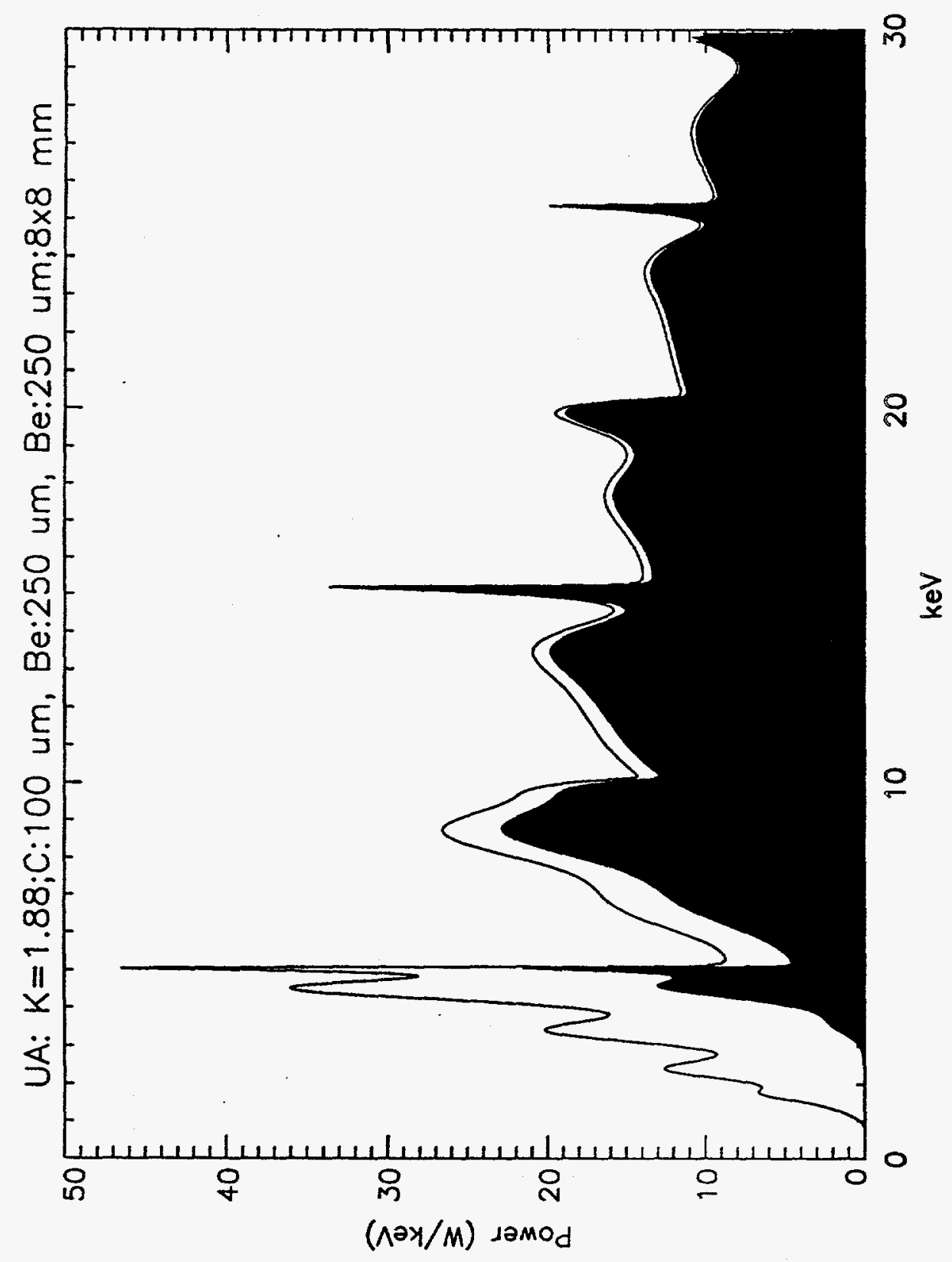

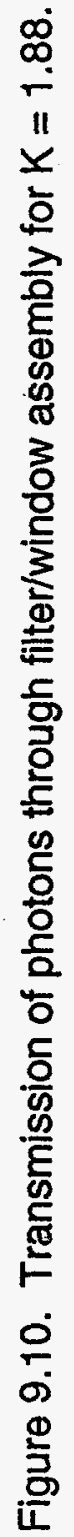




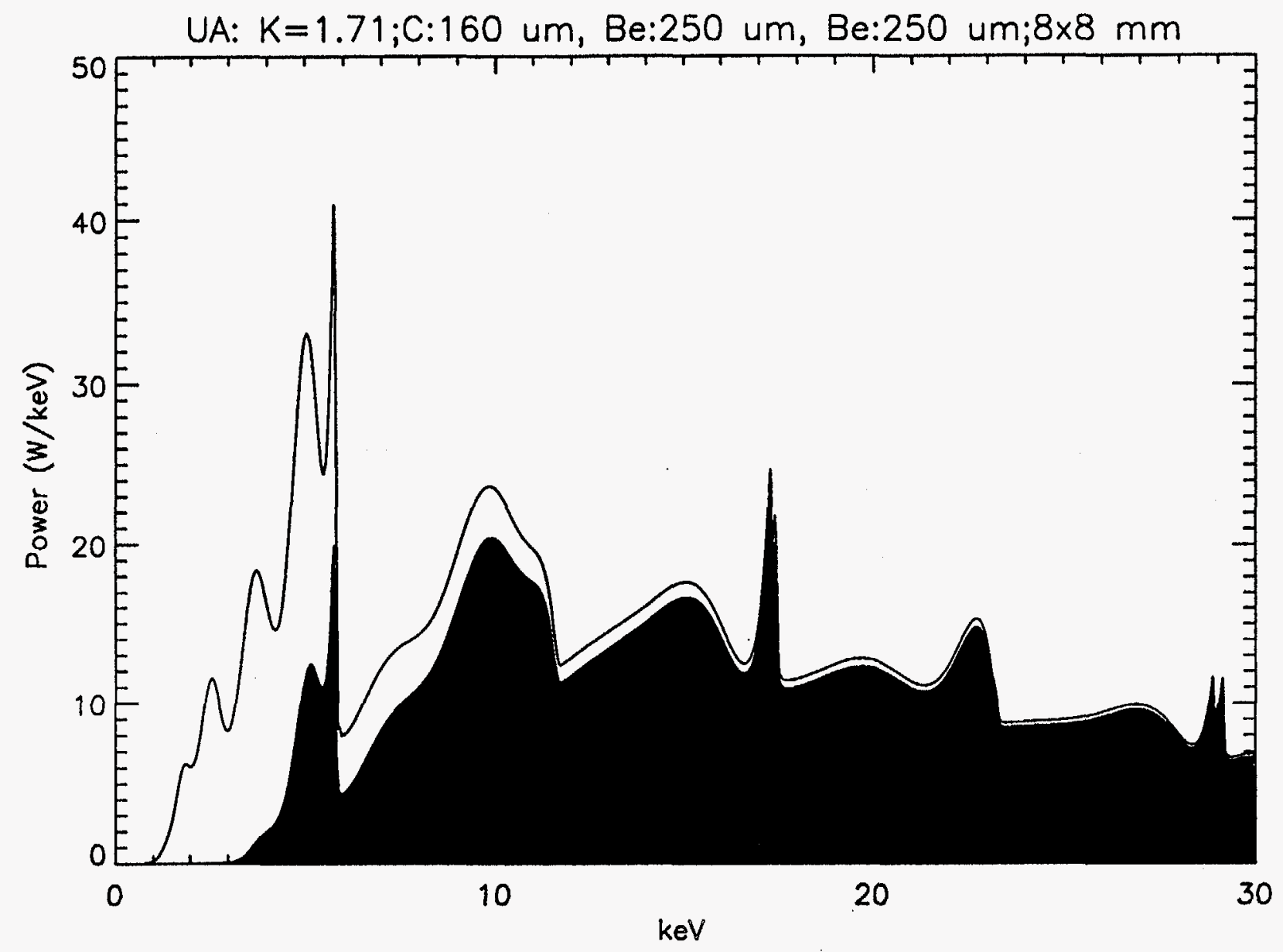

Figure 9.11. Transmission of photons through filter/window assembly for $K=1.71$. 


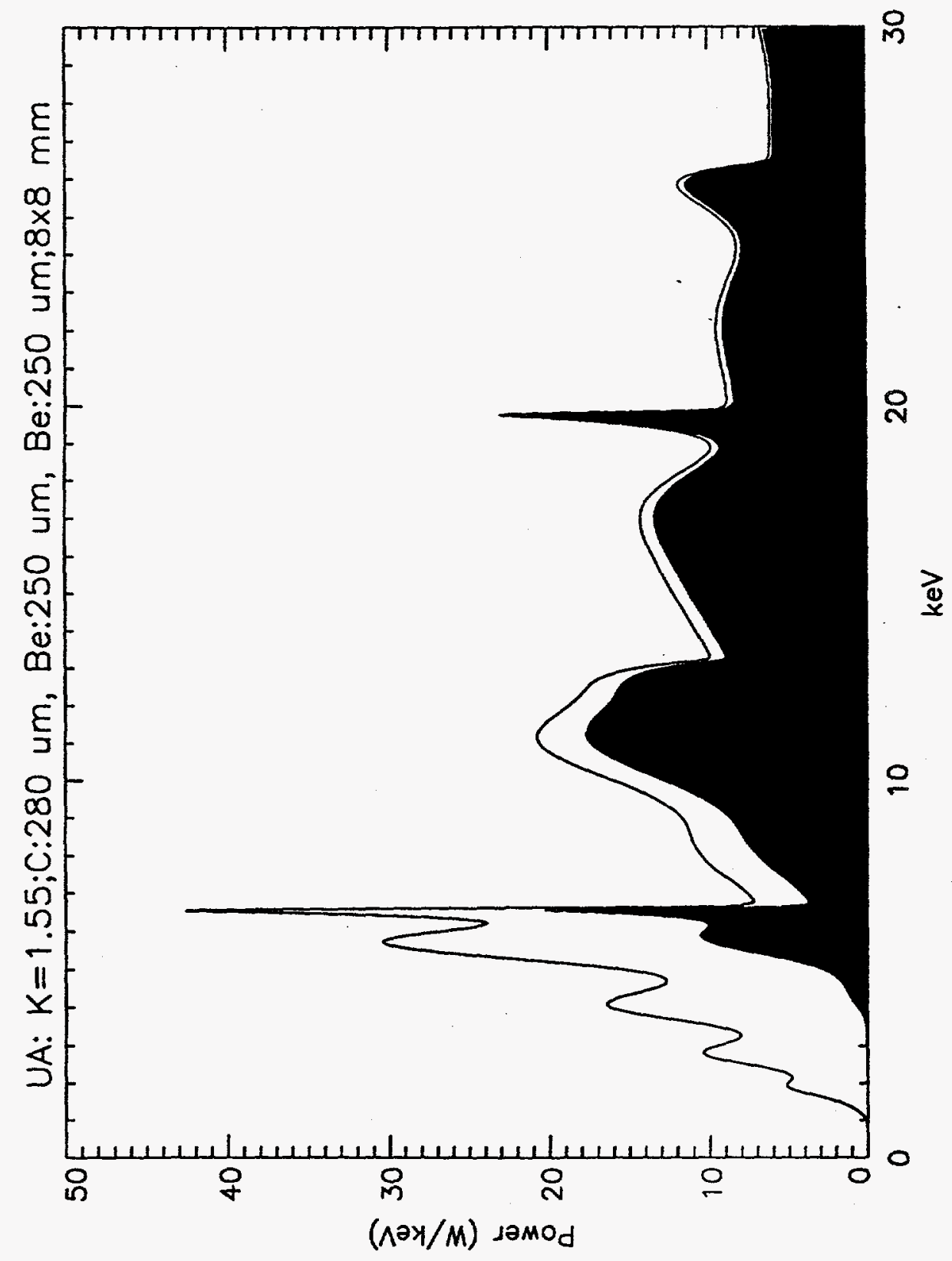

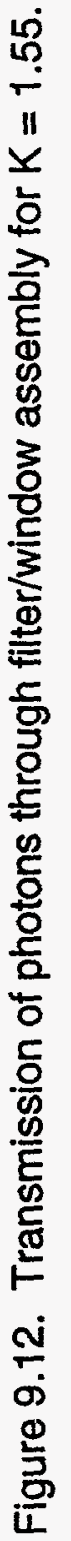




\section{Absorbed power on $\mathrm{C}$ filter and Be window}

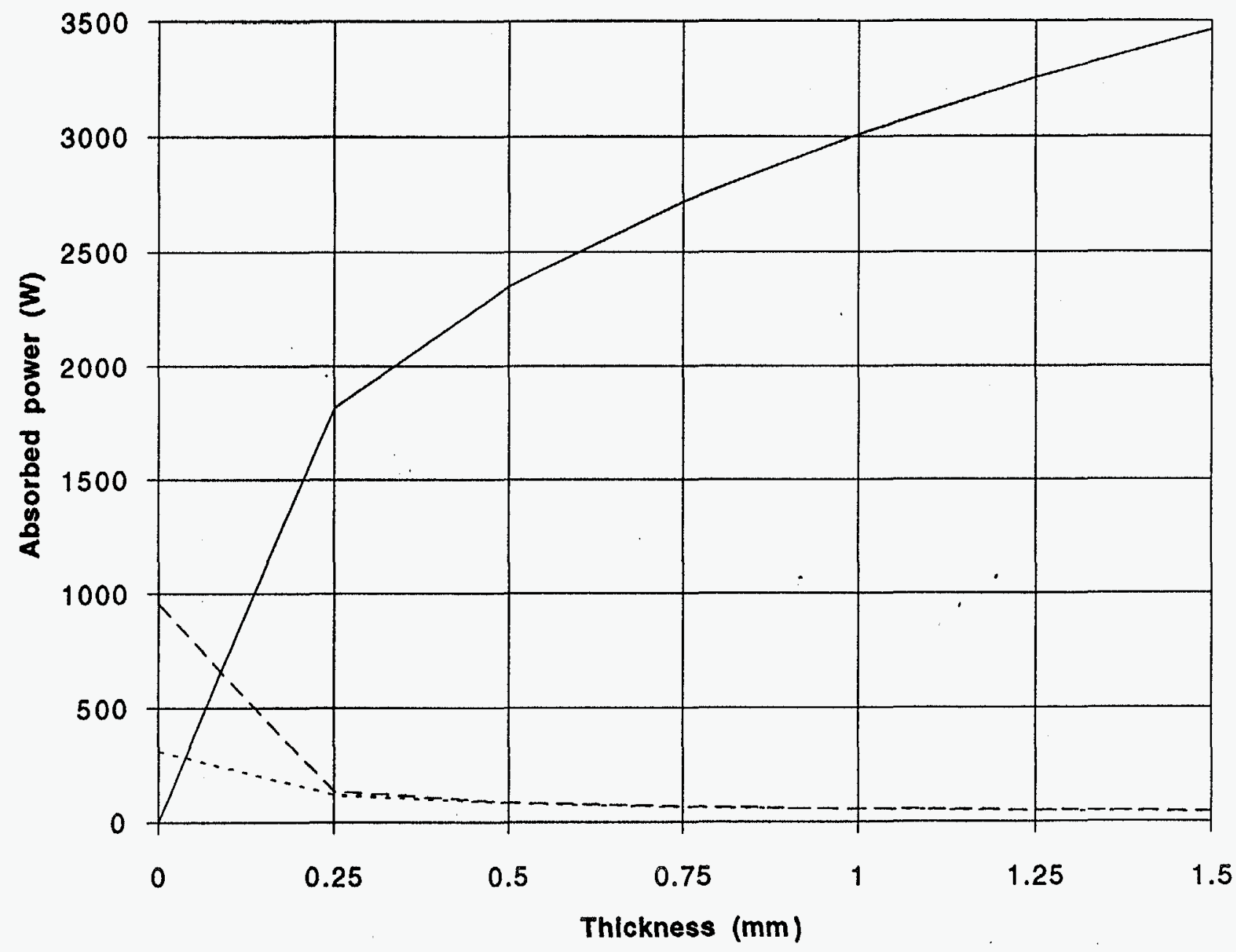

Figure 10.1. Power absorbed by a graphite filter and Be windows. 


\section{Change rate of absorbed power with thickness}

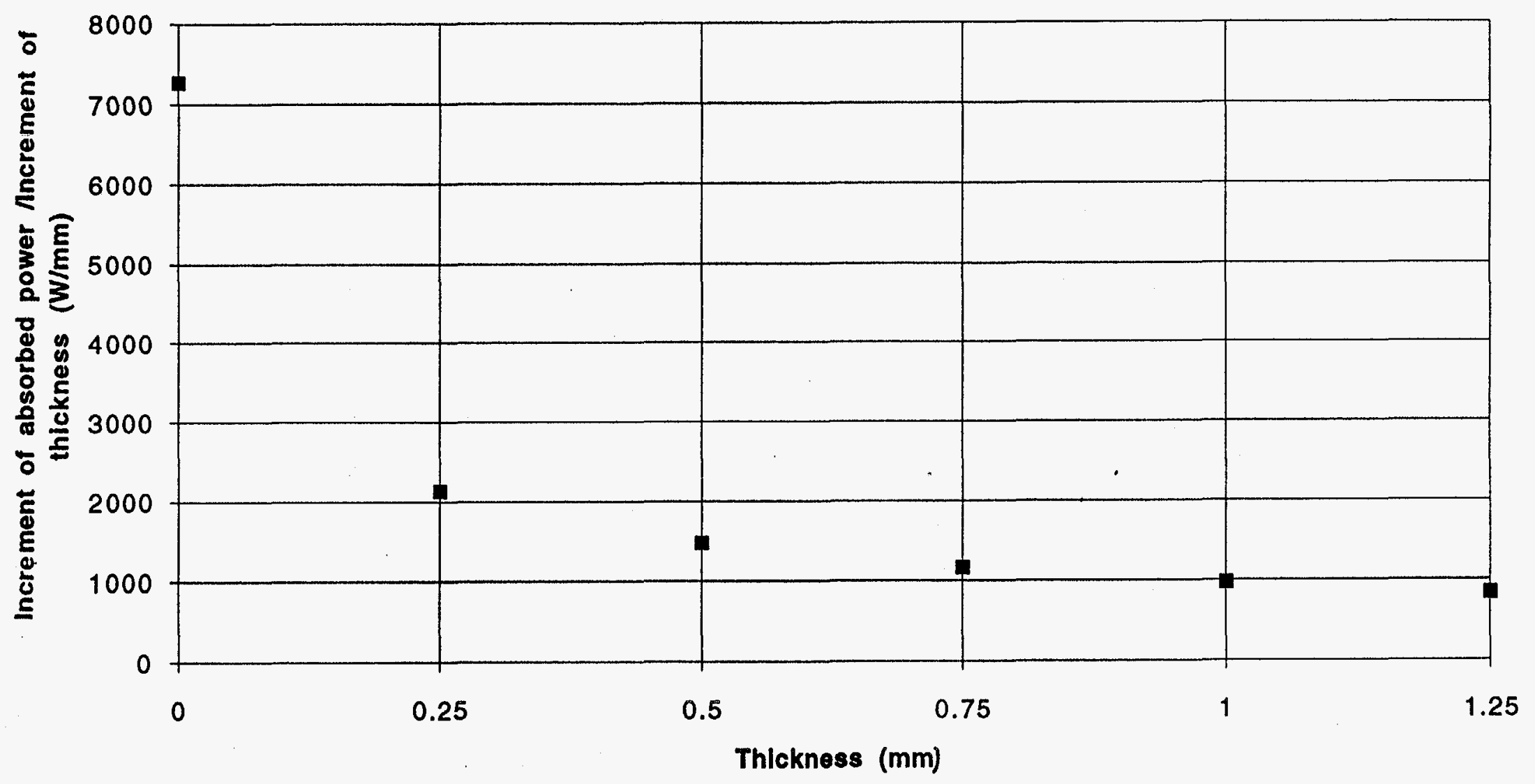

Figure 10.2. Change rate of absorbed power vs. graphite filter thickness. 


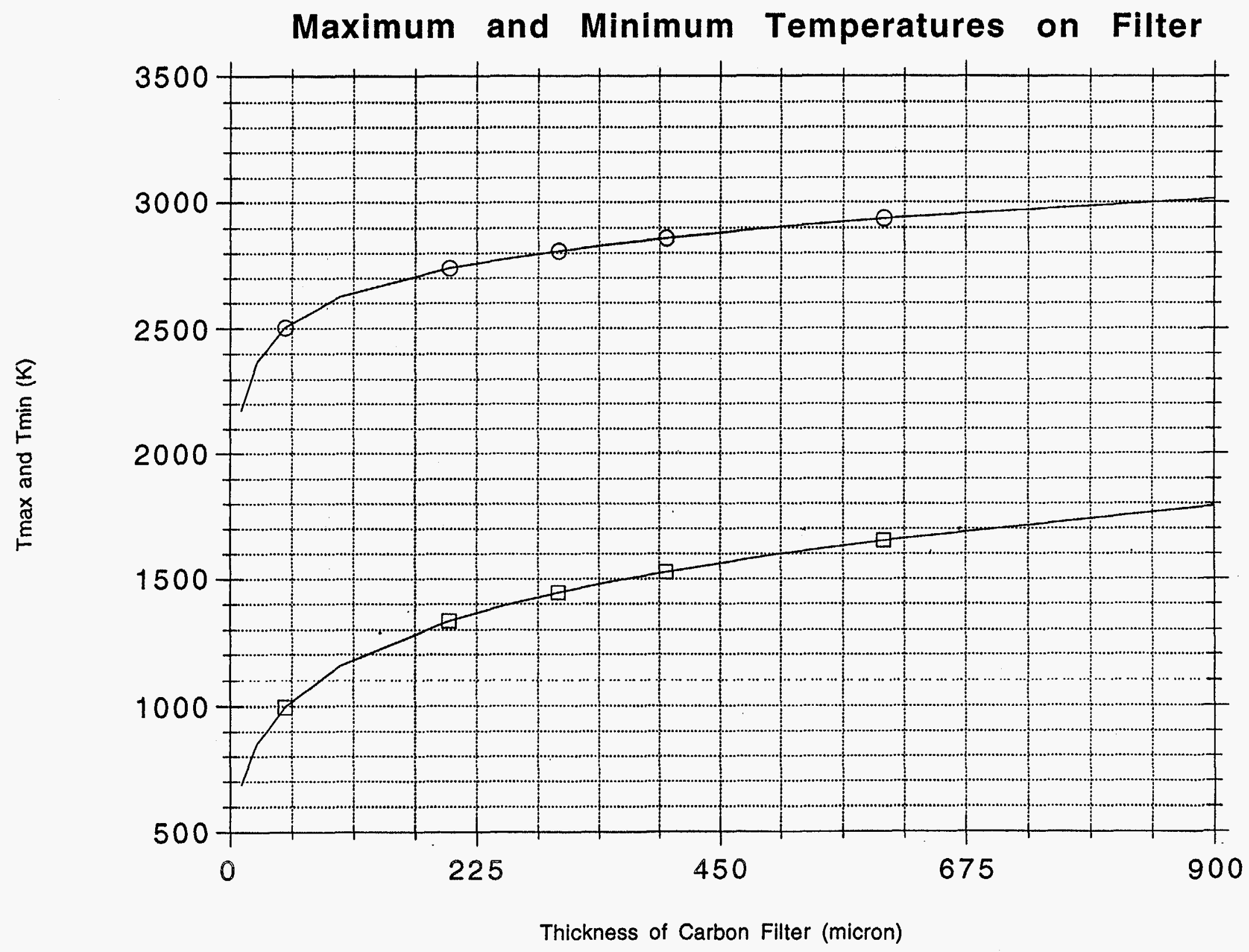

Figure 10.3. Maximum and minimum temperatures of the filter. 


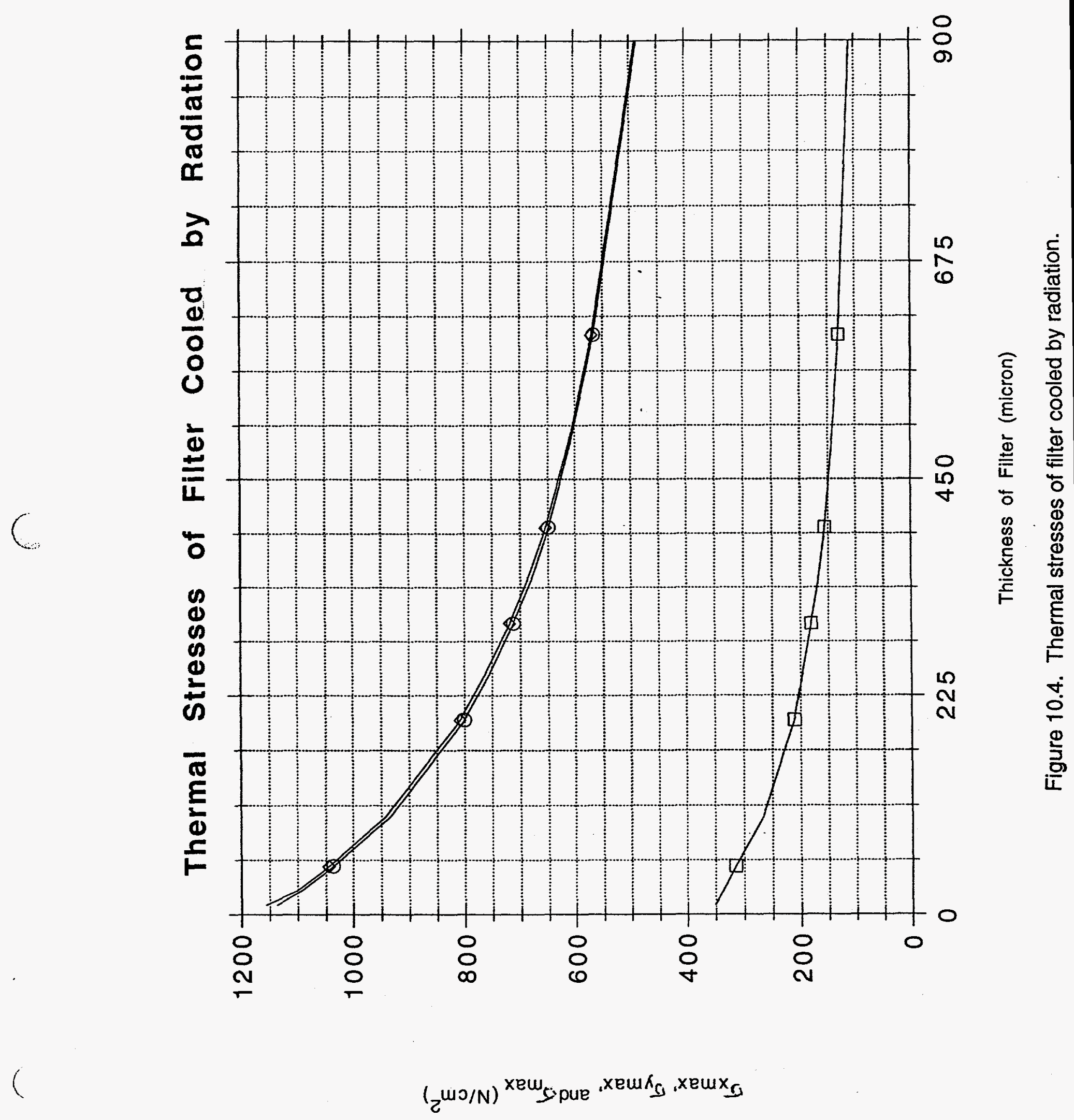




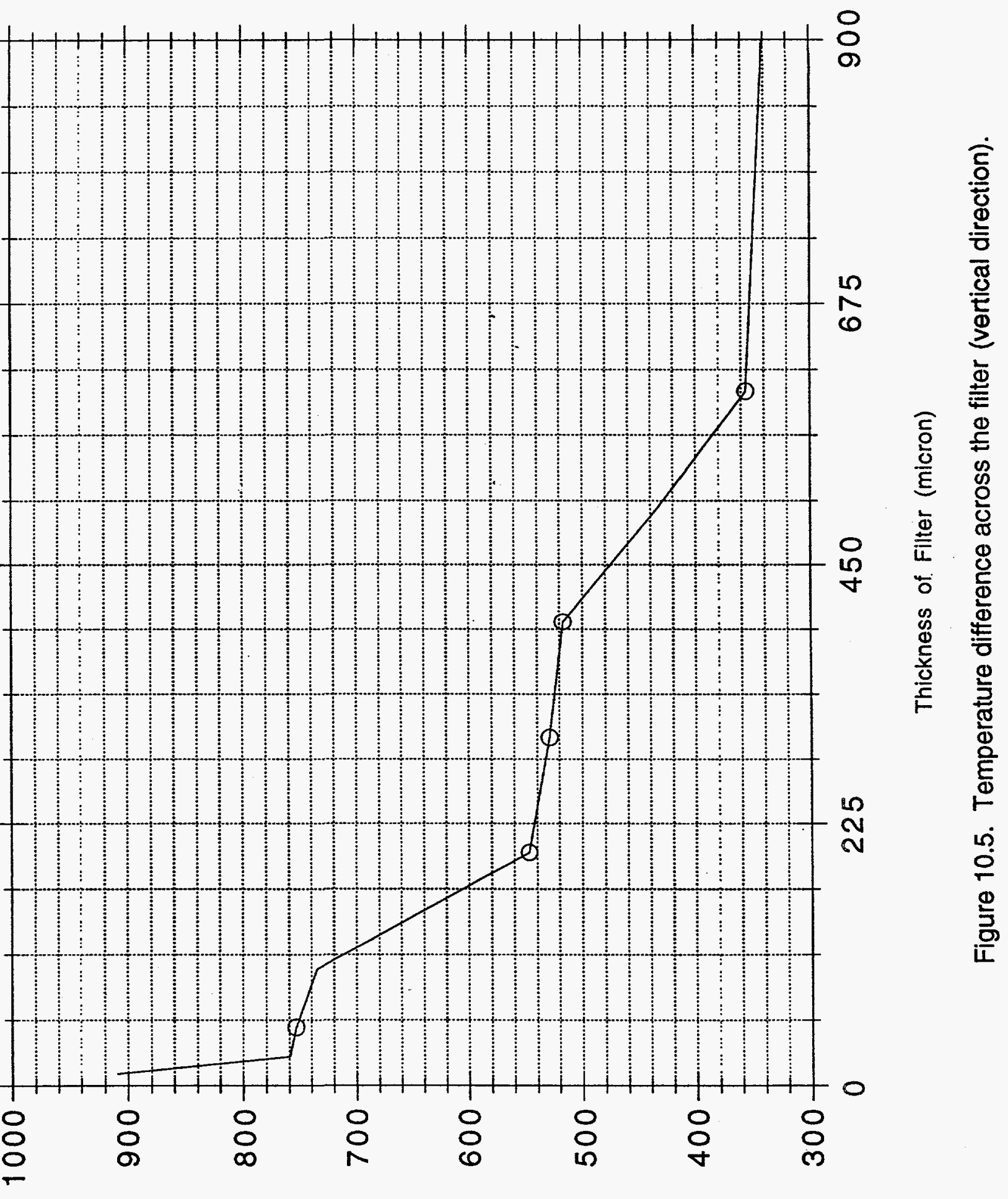




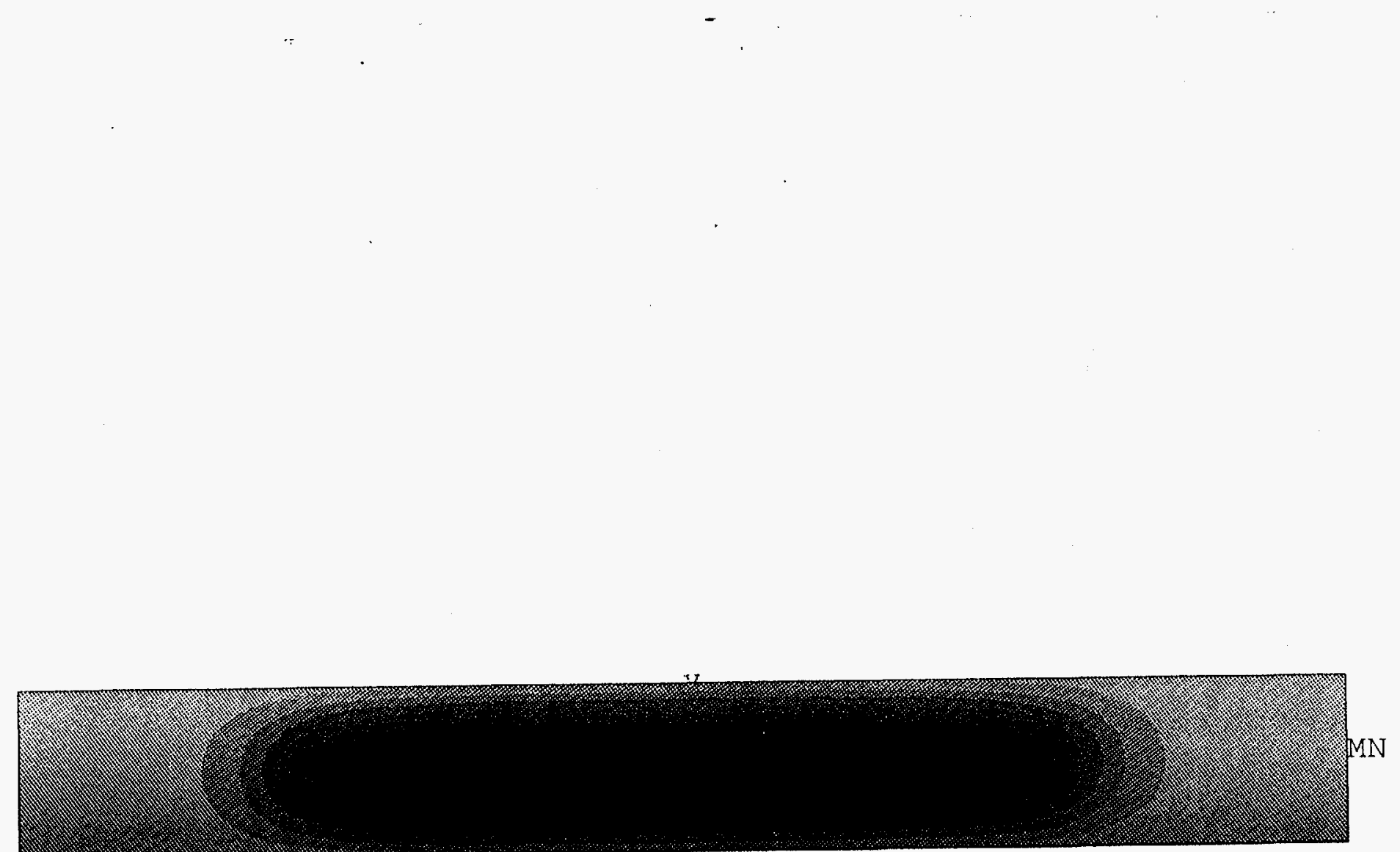

ANSY $4.4 \mathrm{AI}$

JAN 2. 1993

$8: 56: 17$

PLOT NO. 1

POST1 STRESS

STEP $=1$

ITER $=1$

TEMP

SMN $=45.195$

SMX $=136.188$

$\mathrm{ZV}=1$

$\mathrm{DIST}=4.4$

EDGE

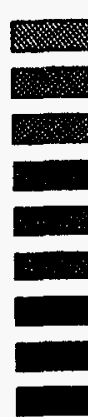

45.195

55.305

65.415

75.526

85.636

95.746

105.857

115.967

126.077

136.188

Figure 10.6. Be window temperature with $300 \mu \mathrm{m}$ graphite filter. 


ANSYS $4.4 \mathrm{~A}$
JAN $27 \quad 1993$
$10: 53: 43$
PLOT NO. 1
POST1 STRESS
STEP $=1$
ITER $=20$
SIGE (AVG)
MIDDLE
DMX $=0.00$
SMN $=14262$
SMX $=32754$

ZV $=1$
DIST $=4.4$
EDGE
A $=15289$
B $=17344$
C $=1.9399$
D $=21453$
E $=23508$
F $=25563$
$G \quad=27617$
$H \quad=29672$
$I \quad=31727$

Figure 10.7. Be window stress with $300 \mu \mathrm{m}$ graphite filter (Mises stress). 
ANSYS $4.4 \mathrm{~A}$

JAN 271993

$10: 53: 45$

PLOT NO

POST1 STRESS

$S T E P=1$

ITER $=20$

SX

MIDDLE

$S$ GLOBAL

$\mathrm{DMX}=0.00$

$S M N=-34503$

$S M X=457.044$

$\mathrm{ZV}=1$

$\mathrm{DIST}=4.4$

EDGE

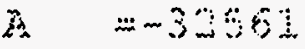

B $--286 \%$

$C \quad=-24792$

D $\quad=-20908$

E $\quad=-17023$

$\mathrm{F} \quad=-13139$

$\mathrm{G}=-9254$

$\mathrm{H} \quad=-5370$

I $=-1485$

Figure 10.8. Be window stress with $300-\mu \mathrm{m}$ graphite filter (stress in $\mathrm{x}$ direction). 
ANSYS 4.47 .

JAN 271993

$10: 53: 49$

PLOT NO.

POST1 STRESS

STEP $=1$

ITER $=20$

SY

(AVG)

MIDDLE

$S$ GLOBAL

$\mathrm{DMX}=0.00$

SMN $=-30666$

$S M X=-6514$

$\mathrm{ZV}=1$

$\mathrm{DIST}=4.4$

EDGE

i. $\quad-2.9324$

I: $=-26641$

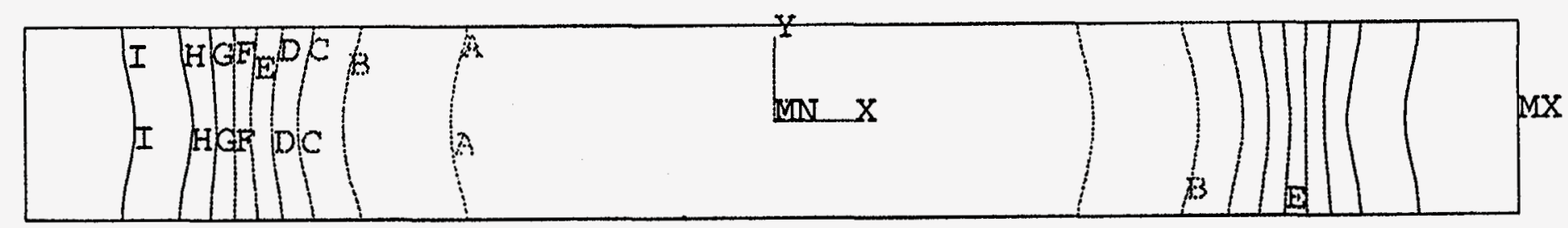

C $=\cdots 23957$

$D=-21274$

E $\quad=-18590$

$F \quad=-15907$

$G \quad=-13223$

$\mathrm{H}=-10539$

$I \quad=-7856$

Figure 10.9. Be window stress with $300-\mu m$ graphite filter (stress in y direction). 